\title{
SEISMIC STABILITY OF CEMENT TREATED GROUND BY TILTING AND DYNAMIC SHAKING TABLE TESTS
}

\author{
MASAKi KITAZUme ${ }^{\text {i) }}$, Kimitoshi HAYANo ${ }^{\text {ii) }}$ and Hideo Hashizume ${ }^{\text {iii) }}$
}

\begin{abstract}
A series of tilting tests and shaking table tests was conducted with a geotechnical centrifuge apparatus to determine the dynamic active earth pressure of cement treated clay ground by investigating the seismic stability of cement treated clay ground having an unsupported vertical slope. In the tilting tests, the horizontal seismic inertia force was simulated statically by tilting the whole model ground in accordance with the horizontal seismic coefficient $k_{\mathrm{h}}$. The tilted model ground was subjected to monotonically increasing centrifugal acceleration until it failed due to the enhanced selfweight. In the shaking table tests, on the other hand, the model ground was subjected to dynamic excitations under a high centrifugal acceleration field. The magnitude of the dynamic excitation was increased stepwise until the model ground failed. It was found from both test results that the model ground failed with a combination of a vertical tensile crack and a straight shear failure plane, which was much different from the failure phenomenon of sandy or clayey ground. It was also found that the conventional pseudo-static limit equilibrium method such as Mononobe-Okabe's earth pressure theory was not able to evaluate the critical height and the failure zone of the model ground accurately. Based on the model test results, a modified pseudo-static limit equilibrium method incorporating the tensile force along the crack plane was proposed in this study. In the method, the critical height and the failure zone of the cement treated ground were influenced by the strength ratio of the tensile strength to the compressive strength of the treated soil. It was found that the proposed method with a suitable strength ratio was able to predict the tilting test results with fairly high accuracy. Also, the proposed method seemed to be able to reasonably explain the shaking test results if the dynamic response acceleration of the model ground was carefully taken into account. Dynamic active earth pressure of cement treated clay ground was also discussed in which the importance of incorporating the failure pattern was emphasized.
\end{abstract}

Key words: centrifuge model test, failure, limit equilibrium method, seismic response, shaking table test, shear strength, soil stabilization, tensile strength, (tilting test) (IGC: D10/E8)

\section{INTRODUCTION}

Because of economical and environmental concerns it has become more difficult in recent years to obtain enough soil to make reclamation for airports, electric power plants, manufacture plants and so on. On the other hand, it has become difficult to find and construct disposal sites for waste subsoil or dredged soil. These circumstances have caused geotechnical engineers at present to use these poor quality materials as filling materials more than they were used one or two decades ago. Recently several soil admixture methods have been developed to improve their properties and to manufacture high quality fill materials. Actually, Horiuchi et al. (1992) and Kawasaki et al. (1992) manufactured fly ash and cement mixtures as a fill material to construct a manmade island for a bridge in Hokkaido, Japan. Tsuchida et al. (1996) manufactured lightweight soil, a mixture of dredged clay, cement and fine air form, to fill behind a sea revetment. Recently, a cement soil mixture manufactured by the Pneumatic Flow Mixing Method as shown in Fig. 1 has been used to construct a man-made island for a new international airport (Kitazume et al., 2000; Kitazume and Sato, 2002).

The deformation and strength characteristics of cement treated soils have been investigated to evaluate the stability of structures adjacent to or buried in the treated ground. For example, Kitazume (1998) investigated the static earth pressure of cement treated fly ash ground by the centrifuge model tests. And he emphasized that the failure pattern of the cement treated ground was much different from that of the sandy or clayey ground and proposed a new calculation method for static earth pressure by incorporating the failure pattern. After the

i) Head, Soil Stabilization Division, Geotechnical and Structural Engineering Department, Port and Airport Research Institute, 3-1-1, Nagase, Yokosuka 239-0826, Japan (kitazume@pari.go.jp).

ii) Senior Researcher, ditto.

iii) Manager, Technical Division, GEODESIGN Co., Ltd.

Manuscript was received for review on December 18, 2002.

Written discussions on this paper should be submitted before July 1, 2004 to the Japanese Geotechnical Society, Sugayama Bldg. 4F, Kanda Awaji-cho 2-23, Chiyoda-ku, Tokyo 101-0063, Japan. Upon request the closing date may be extended one month. 


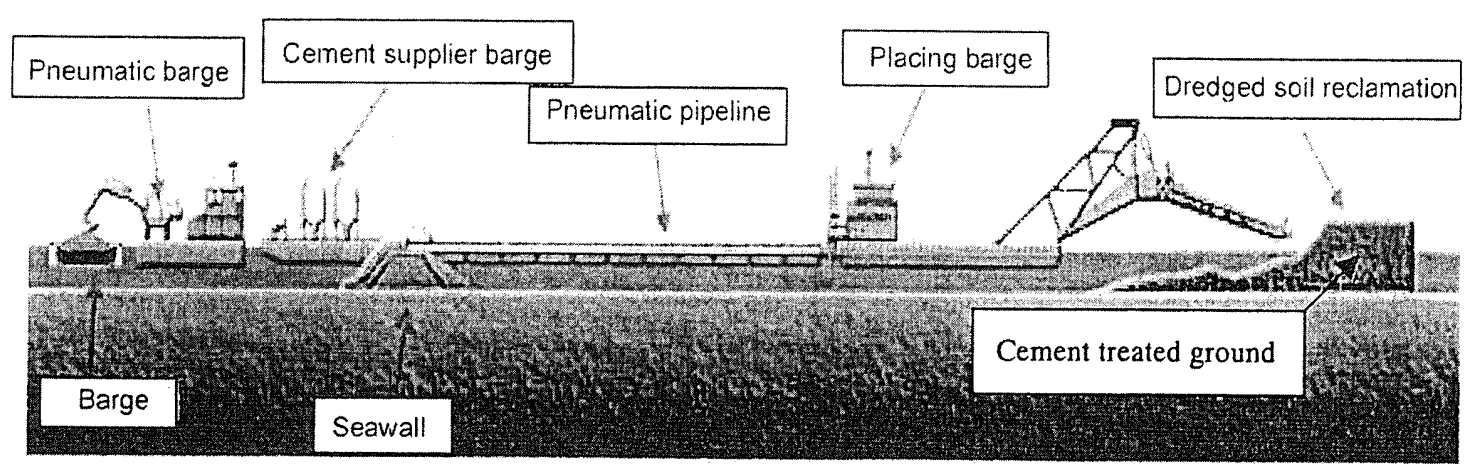

Fig. 1. Schematic view of Pneumatic Flow Mixing Method (Kitazume and Sato, 2002)

Hyogoken-Nambu earthquake in 1995, many design codes for the seismic stability were revised in Japan, so that seismic stability must be evaluated more precisely. The dynamic earth pressure of sandy or clayey ground is usually calculated by a pseudo-static limit equilibrium method based on the Mononobe-Okabe's method (Okabe, 1924; Mononobe and Matsuo, 1929). This calculation method is also applied to the cement treated ground, although its applicability has not been thoroughly clarified.

In this paper, the failure pattern and the dynamic earth pressure of the cement treated clay ground subjected to earthquake motion were investigated by conducting both tilting and shaking table tests on the Port and Airport Research Institute (PARI) geotechnical centrifuge apparatus. It is well known that the complicated interaction between a retaining wall and a model ground during the excitation makes it very difficult to understand the dynamic earth pressure of the ground accurately and precisely. Therefore in this study, the dynamic earth pressure was studied by investigating the seismic stability of cement treated clay ground having an unsupported vertical slope. In the tilting tests, a model ground tilted in accordance with the prescribed horizontal coefficient $k_{\mathrm{h}}$ was subjected to monotonically increasing centrifugal acceleration until it failed due to the enhanced selfweight. In the shaking table tests, the model ground was subjected to several dynamic excitations in centrifugal acceleration of $35 \mathrm{~g}$ or $40 \mathrm{~g}$ until it failed. The applicability of the conventional pseudo-static limit equilibrium method based on Mononobe-Okabe's method to the cement treated ground was examined based on the model test results, where the calculated critical height of the ground did not coincide well with the model test results. Then a modified pseudo-static limit equilibrium method incorporating the tensile force along the crack plane was proposed to evaluate the critical height and the failure zone of the cement treated clay ground more accurately. Furthermore, the dynamic effects on the stability of the cement treated ground were discussed based on the comparison of model ground behavior in the shaking table tests and the tilting tests.

\section{CENTRIFUGE MODEL TESTS}

Centrifuge dynamic shaking table tests have been frequently carried out to investigate the full-scale seismic behavior of ground or structures (e.g. Whiteman, 1988; Steedman, 1991). The dynamic excitations with various amplitudes of acceleration are usually loaded to the same model ground until failure occurs. Many dynamic excitations with a small increment of acceleration for each step are required in order to detect the critical dynamic acceleration with high accuracy when the model ground is going to fail. However, it is practically very difficult and many dynamic excitations to the model ground behavior can cause serious detrimental influences. A quasi-static loading technique has also been employed to investigate the seismic stability of ground where the model ground is subjected to horizontal inertia force statically by tilting the model ground. This technique has been often applied not only in 1g-laboratory model tests (e.g. Tatsuoka et al., 1998) but also in centrifuge model tests (Mikasa et al., 1969). This technique has an advantage to detect ground failure easily, if the tilting angle or the centrifugal acceleration is increased monotonically.

In this study, the quasi-static loading technique was employed in the tilting tests at first to detect the failure behavior of the cement treated ground. To simplify the loading device for horizontal inertia force, the model ground placed on an inclined base was subjected to monotonically increasing centrifuge acceleration until it failed, instead of tilting the model ground under a high centrifugal acceleration. Various horizontal inertia forces corresponding to the prescribed seismic coefficients $k_{\mathrm{h}}$ were applied to the model grounds by changing the tilting angle $\alpha\left(=\tan ^{-1} k_{\mathrm{h}}\right)$ of the model ground.

The dynamic shaking table tests were then performed on the centrifuge to confirm the findings in the tilting tests. The model ground was subjected to several dynamic excitations with 50 sinusoidal waves of $2 \mathrm{~Hz}$ in a prototype scale under centrifugal acceleration of $35 \mathrm{~g}$ or $40 \mathrm{~g}$. The amplitude of the input table acceleration was increased stepwise until the model ground failed.

Figure 2 schematically shows a sort of loading path of the ground height and the horizontal seismic coefficient $k_{\mathrm{h}}$ in the tilting tests and the shaking table tests until failure 
of the model grounds. In the titling test, the ground height, which is obtained by multiplying the height of model ground and centrifugal acceleration, increases monotonically with constant horizontal seismic coefficient. On the other hand, in the shaking table test, the seismic coefficient increases with constant ground height. Because the ground deformation which takes place before the failure is quite small, as described later, it can be assumed that a unique failure line is obtained in the two tests irrespective of the loading path.

The centrifuge used for both the tilting and the shaking table tests was the Port and Airport Research Institute (formerly Port and Harbour Research Institute) Mark II Geotechnical centrifuge. The centrifuge has a maximum acceleration of $113 \mathrm{~g}$, a maximum effective radius of $3.8 \mathrm{~m}$ and a maximum payload of $2710 \mathrm{~kg}$. Kitazume and Miyajima (1996) have described the centrifuge and surrounding equipment in detail.

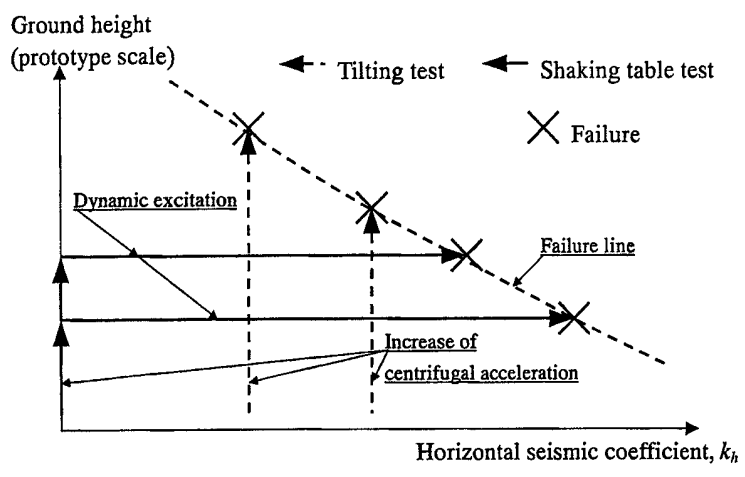

Fig. 2. Relationships between ground height and horizontal seismic coefficient in the tilting tests and the shaking table tests
Model Ground Preparation and Testing Procedure for Tilting Tests

The model ground set up for the tilting test is schematically shown in Fig. 3. A series of tilting tests was conducted by changing the tilting angle $\alpha$ and the strength of the model ground, as summarized in Table 1. A rigid specimen box had inside dimensions of $50 \mathrm{~cm}$ in length, $20 \mathrm{~cm}$ in width and $35 \mathrm{~cm}$ in height. The inner surfaces of the box were lubricated with a mixture of silicone grease and silicone oil to minimize the friction between the box and the model ground. The box had a Perspex window of $5 \mathrm{~cm}$ in thickness to observe the model ground behavior. An inclined steel base was put on the bottom of the box to simulate the horizontal inertia force, on which the model ground was placed. A pair of accelerometers was set on the swinging platform of the geotechnical centrifuge to measure centrifugal acceleration accurately.

The model ground was prepared as follows. Kawasaki marine clay was thoroughly mixed with de-aired water

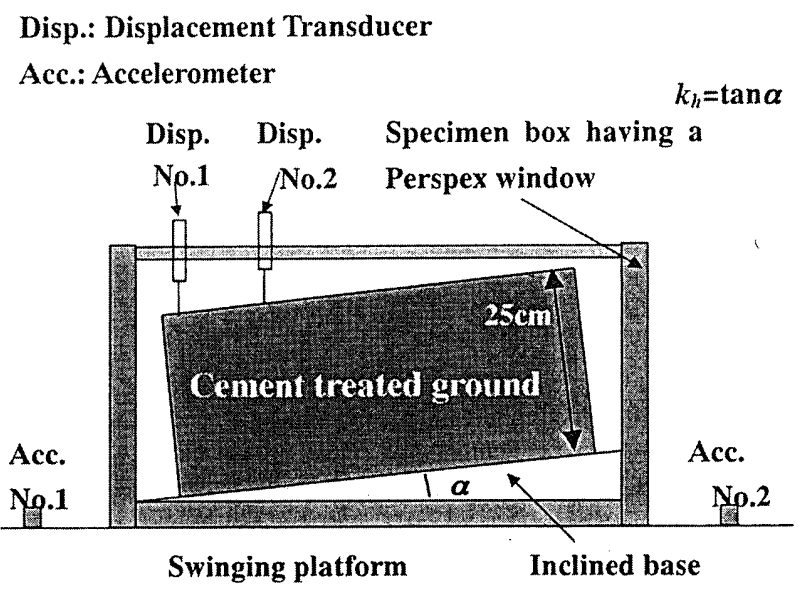

Fig. 3. Schematic view of model ground in tilting test

Table 1. Tilting test conditions

\begin{tabular}{|c|c|c|c|c|c|c|}
\hline \multirow[b]{2}{*}{ Case No. } & \multirow{2}{*}{$\begin{array}{c}\text { Horizontal } \\
\text { seismic } \\
\text { coefficient, } \\
k_{\mathrm{h}}\end{array}$} & \multicolumn{4}{|c|}{ Property of model ground } & \multirow{2}{*}{$\begin{array}{c}\text { Centrifugal } \\
\text { acceleration } \\
\text { at failure, } \\
G_{\mathrm{f}}(\mathrm{g})\end{array}$} \\
\hline & & $\begin{array}{l}\text { Height } \\
(\mathrm{cm})\end{array}$ & $\begin{array}{l}\text { Length } \\
\text { (cm) }\end{array}$ & $\begin{array}{c}\text { Unconfined } \\
\text { compressive } \\
\text { strength, } q_{\mathrm{u}}\left(\mathrm{kN} / \mathrm{m}^{2}\right)\end{array}$ & $\begin{array}{c}\text { Weight per } \\
\text { unit volume, } \\
\gamma\left(\mathrm{kN} / \mathrm{m}^{3}\right)\end{array}$ & \\
\hline No. PST01 & 0.0 & 25 & 40 & 94.1 & 13.0 & 39.4 \\
\hline No. PST02 & 0.0 & 25 & 40 & 117.5 & 13.2 & 51.2 \\
\hline No. PST03 & 0.0 & 25 & 40 & 158.4 & 13.3 & 83.6 \\
\hline No. PST04. & 0.0 & 25 & 40 & 175.7 & 13.2 & 71.2 \\
\hline No. PST05 & 0.05 & 24.3 & 40 & 38.5 & 13.3 & 23.0 \\
\hline No. PST06 & 0.1 & 25 & 40 & 46.4 & 13.1 & 23.9 \\
\hline No. PST07 & 0.1 & 25 & 40 & 136.1 & 13.4 & 53.3 \\
\hline No. PST08 & 0.15 & 25 & 40 & 42.8 & 13.2 & 18.7 \\
\hline No. PST09 & 0.15 & 25 & 34 & 194.2 & 13.1 & 75.0 \\
\hline No. PST10 & 0.2 & 25 & 40 & 41.0 & 13.3 & 18.8 \\
\hline No. PST11 & 0.2 & 25 & 40 & 131.8 & 13.3 & 51.0 \\
\hline No. PST12 & 0.2 & 25 & 40 & 152.1 & 13.3 & 58.3 \\
\hline No. PST13 & 0.2 & 25 & 40 & 166.7 & 13.3 & 61.1 \\
\hline No. PST14 & 0.25 & 25 & 34 & 127.8 & 13.1 & 44.5 \\
\hline No. PST15 & 0.25 & 25 & 34 & 175.0 & 13.0 & 61.6 \\
\hline No. PST16 & 0.3 & 25 & 34 & 137.5 & 13.2 & 43.1 \\
\hline No. PST17 & 0.3 & 25 & 34 & 158.4 & 13.0 & 52.2 \\
\hline
\end{tabular}


Table 2. Physical properties of Kawasaki clay

\begin{tabular}{l|l|l|l} 
Density of soil particles, $\rho_{\mathrm{s}}$ & 2.65 & Liquid limit, $w_{\mathrm{L}}$ & $83.4 \%$ \\
Sand content $(>75 \mu \mathrm{m})$ & $2.7 \%$ & Plastic limit, $w_{\mathrm{p}}$ & $38.6 \%$ \\
Silt content $(5-75 \mu \mathrm{m})$ & $44.8 \%$ & Plasticity index, $I_{\mathrm{p}}$ & 44.8 \\
Clay content $(<5 \mu \mathrm{m})$ & $52.2 \%$ & &
\end{tabular}

Table 3. Shaking test conditions

\begin{tabular}{c|c|c|c|c|c}
\hline & & \multicolumn{4}{|c}{ Property of model ground } \\
\cline { 4 - 6 } Case No. & $\begin{array}{c}\text { Centrifugal } \\
\text { acceleration, } \\
(\mathrm{g})\end{array}$ & $\begin{array}{c}\text { Height, } \\
H \\
(\mathrm{~cm})\end{array}$ & $\begin{array}{c}\text { Length, } \\
L \\
(\mathrm{~cm})\end{array}$ & $\begin{array}{c}\text { Unconfined } \\
\text { compressive } \\
\text { strength, } \\
q_{\mathrm{u}}\left(\mathrm{kN} / \mathrm{m}^{2}\right)\end{array}$ & $\begin{array}{c}\text { Weight } \\
\text { per unit } \\
\text { volume, } \\
\gamma\left(\mathrm{kN} / \mathrm{m}^{3}\right)\end{array}$ \\
\hline No. DS01 & 35 & 28 & 45 & 142.4 & 13.2 \\
No. DS02 & 40 & 30 & 48 & 122.4 & 13.3 \\
\hline
\end{tabular}

for 30 minutes to make a uniform slurry with a water content of $160 \%$, whose physical properties are summarized in Table 2. Then, binder factor $a_{\mathrm{w}}$ of 6 to $12 \%$ Normal Portland cement was added to the slurry and mixed for 10 minutes; $a_{\mathrm{w}}$ was defined as the ratio of dry weight of cement to that of soil. The soil cement mixture was poured into either of two rigid mold boxes depending upon the test condition, whose inside dimensions were $40 \mathrm{~cm}$ in length, $20 \mathrm{~cm}$ in width and $25 \mathrm{~cm}$ in height or $34 \mathrm{~cm}$ in length, $20 \mathrm{~cm}$ in width and $25 \mathrm{~cm}$ in height, respectively. The model ground for higher inertia force was manufactured in the smaller mold box, because of the size limitation of the specimen box. The model ground was sealed tightly to minimize water evaporation from the model ground. After being cured for two weeks in the air-conditioned laboratory at a constant temperature of 20 degree, the treated soil was removed from the mold and placed on the inclined steel base. The model ground had a free surface at the two vertical faces without any support. The model ground thus prepared was subjected to monotonically increasing centrifugal acceleration until it failed due to the enhanced selfweight. The vertical displacements at the crown of the model ground were measured with the displacement transducers. During and after the test, the failure pattern of the ground was carefully observed. After each test, unconfined compression tests (UC tests) were conducted on the specimen retrieved from the model ground and trimmed to a diameter of $5 \mathrm{~cm}$ and a height of $10 \mathrm{~cm}$.

\section{Model Ground Preparation and Testing Procedure of Shaking Table Tests}

Two shaking table tests were also conducted by changing the size and the strength of the model ground, as summarized in Table 3, to confirm the findings in the tilting tests and to investigate the failure pattern and the dynamic response characteristics. Testing procedures for the shaking table tests consisted of three steps; (1) preparation of model ground, (2) increase of centrifugal acceleration, (3) shaking of model ground. Figure 4 shows a typical cross-section of model ground, which was prepared in a similar manner as described for those of the

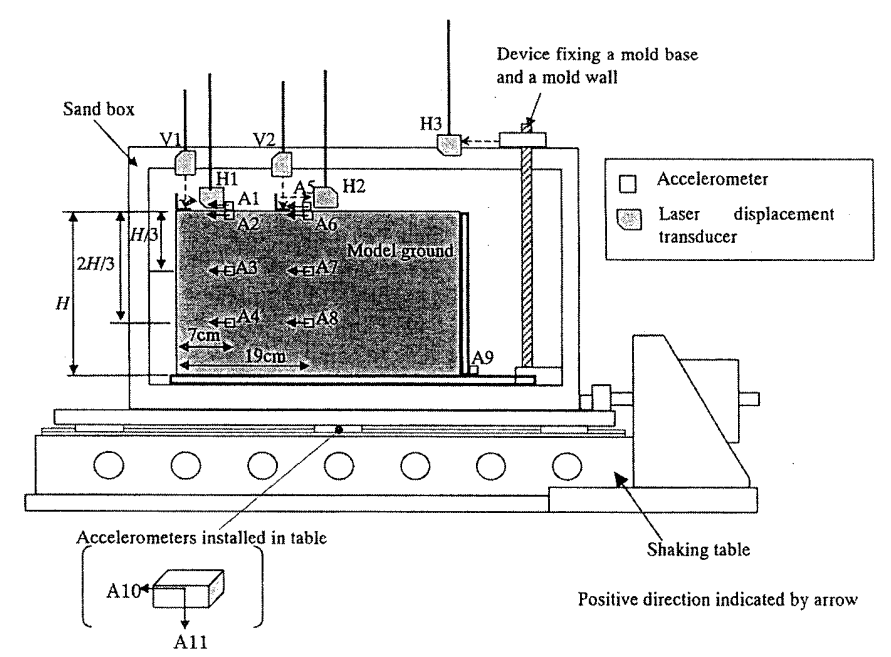

Fig. 4. Model configuration in shaking table test

tilting tests, except the supporting condition of the ground. The front face (left hand side in the figure) of the treated soil block was in free condition without any support, while the rear face (right hand side) was supported with a steel plate to prevent failure during excitation. In order to measure the horizontal seismic response, six accelerometers denoted by A2-A4 and A6-A8 were installed within the model ground at three different depths. In setting the accelerometers, two dry spaghetti noodles were stood vertically at the prescribed position in the mold at first, to which three accelerometers were glued at the prescribed depth and direction. Then, the soil cement mixture was poured into the mold carefully not to cause the noodles to deflect. The noodles buried in the mixture were gradually soaked. The position of the accelerometers was confirmed to be at the prescribed positions by visual observation after the loading test. The other two accelerometers denoted by $\mathrm{A} 1$ and $\mathrm{A} 2$ were glued on the ground surface after hardening of the mixture. An accelerometer A9 was also set on the mold base to measure the base acceleration. Five displacement transducers were set to measure the vertical and the horizontal displacements of the ground and also the horizontal movement of the specimen box. After placing the model ground in the specimen box having inside dimensions of $60 \mathrm{~cm}$ in length, $20 \mathrm{~cm}$ in width and $41 \mathrm{~cm}$ in height, the specimen box on the shaking table was brought up to either $35 \mathrm{~g}$ or $40 \mathrm{~g}$ centrifugal acceleration. Immediately after reaching a targeted acceleration, the model ground was subjected to several dynamic excitations of 50 sinusoidal waves with a frequency of $2 \mathrm{~Hz}$ in a prototype scale. The amplitude of the input table acceleration was increased stepwise until the model ground failed. After each test, unconfined compression tests (UC tests) were conducted on the specimen retrieved from the model ground and trimmed to a diameter of $5 \mathrm{~cm}$ and a height of $10 \mathrm{~cm}$. 


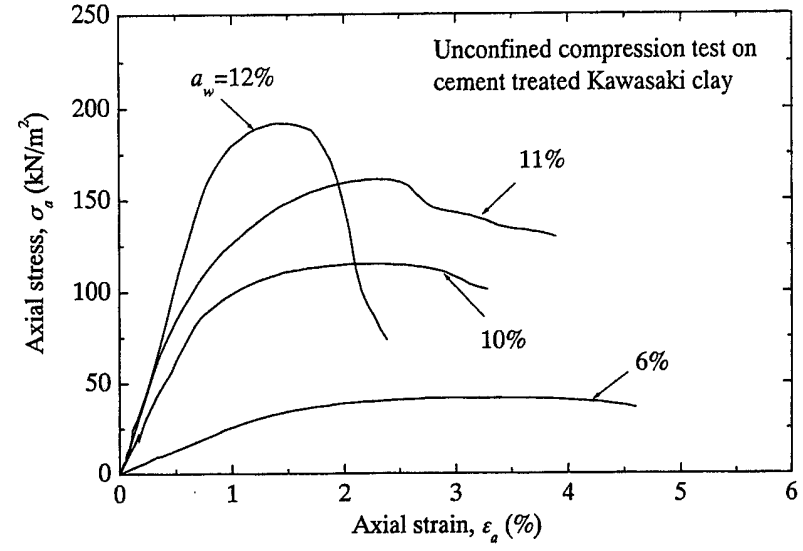

Fig. 5. Stress-strain curves of cement treated Kawasaki clay in UC tests

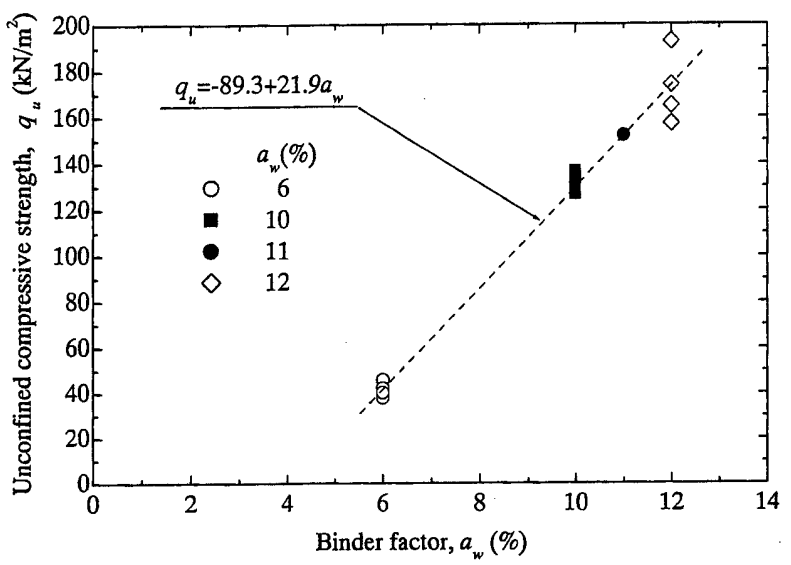

Fig. 6. The relationship between the cement admixture content $a_{\mathrm{w}}$ and unconfined compressive strength $q_{\mathrm{u}}$

\section{Compressive and Tensile Strength Characteristics of Cement Treated Clay}

To investigate the stress-strain behavior of the cement treated soil and to estimate the strength ratio of tensile and compressive strengths of the cement treated soil, a series of UC and spilt tests was conducted prior to the centrifuge model tests on the specimen having $5 \mathrm{~cm}$ in diameter and $10 \mathrm{~cm}$ in height. The specimens were prepared according to the Standard of Japanese Geotechnical Society (1990) and after being sealed, they were cured in the air-conditioned laboratory at a constant temperature of 20 degree.

Typical stress-strain curves of the treated soil for various $a_{\mathrm{w}}$ values are shown in Fig. 5 . In the curve of $a_{\mathrm{w}}=6 \%$, the axial stress $\sigma_{\mathrm{a}}$ increases gradually to a maximum as the axial strain $\varepsilon_{\mathrm{a}}$ increases, but shows no clear peak value. The curve of $a_{\mathrm{w}}=12 \%$, on the other hand, shows a rapid increase in the $\sigma_{\mathrm{a}}$ with increasing $\varepsilon_{\mathrm{a}}$, and also shows a clear peak. The axial strain at failure is a quite small value of the order of a few percent. The relationship between the $q_{\mathrm{u}}$ and $a_{\mathrm{w}}$ values is shown in Fig. 6, where a regressing line of the measured data is also plotted. It is found that the increase of cement amount causes the treated soil strength high and also changes the character-

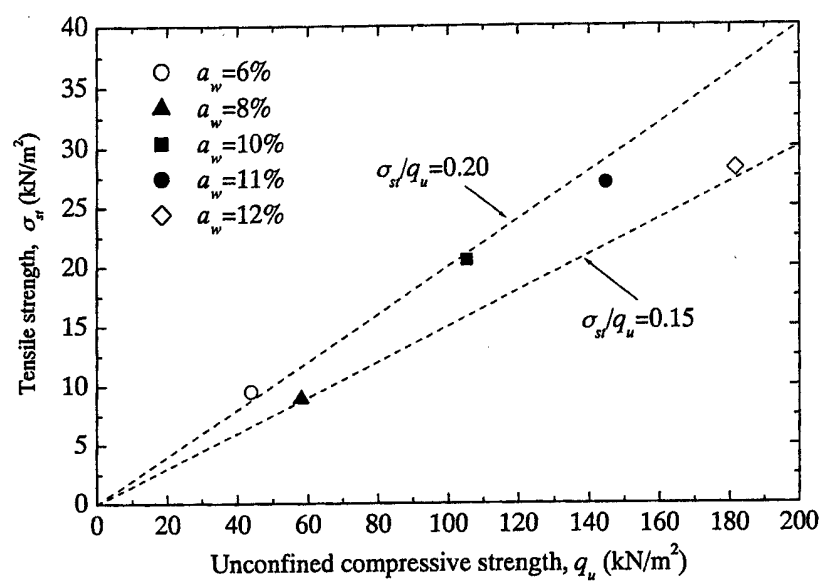

Fig. 7. The relationship between the unconfined compressive strength $q_{\mathrm{u}}$ and tensile strength $\sigma_{\mathrm{st}}$

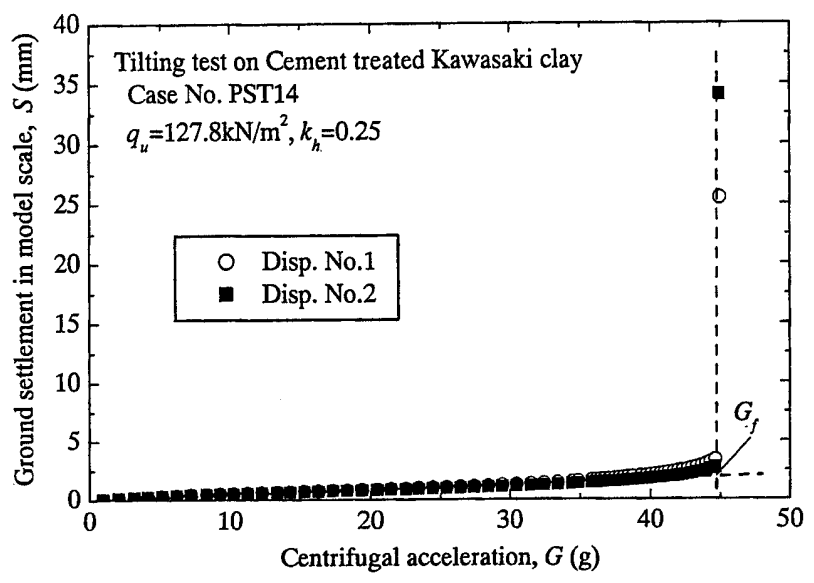

Fig. 8. Ground settlement with centrifugal acceleration in tilting test

istics of the cement treated soil from ductile to brittle behavior. A similar phenomenon was also found for cement treated fly ash (Kitazume, 1998).

As the compressive deflection at failure in the split test was quite small, the tensile strength $\sigma_{\text {st }}$ was obtained by a similar manner of concrete engineering and is plotted against the $q_{\mathrm{u}}$ in Fig. 7. The strength ratio $\sigma_{\mathrm{st}} / q_{\mathrm{u}}$ is quite small, of 0.18 on average, and almost constant irrespective of $q_{\mathrm{u}}$. This value of the ratio is of the same order as the value obtained in various cement treated soils (Terashi et al., 1979), but slightly larger than the value on lightly cemented sand (Dass et al., 1994).

\section{FAILURE PATTERN OF CEMENT TREATED CLAY GROUND}

During the tilting tests, the vertical displacements of the model ground were measured at its crown. These did not measure the ground settlement because of the tilting of the model ground. The ground settlement $S$, perpendicular to the model ground surface, was calculated by multiplying the measured vertical displacement and cos $\alpha$, where $\alpha$ was the tilting angle of the model ground. Figure 8 shows the ground settlement $S$ in a model scale 


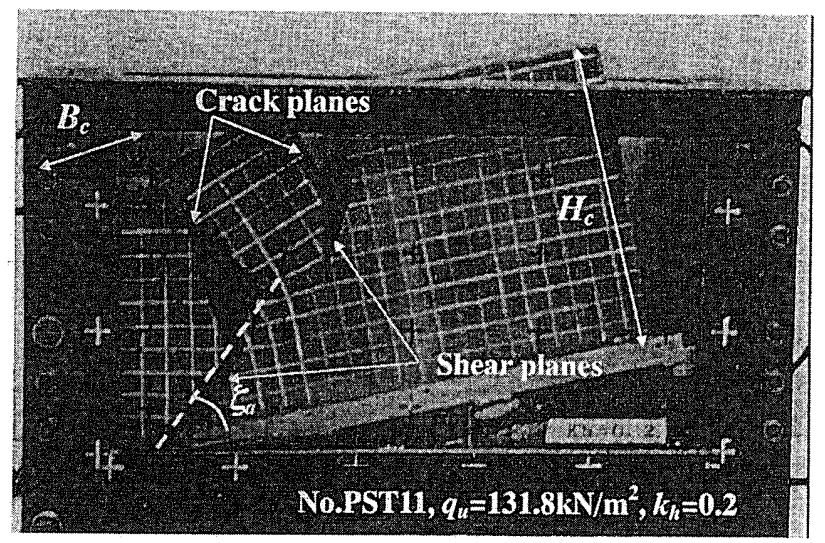

Fig. 9. Typical failure pattern of model ground in tilting test

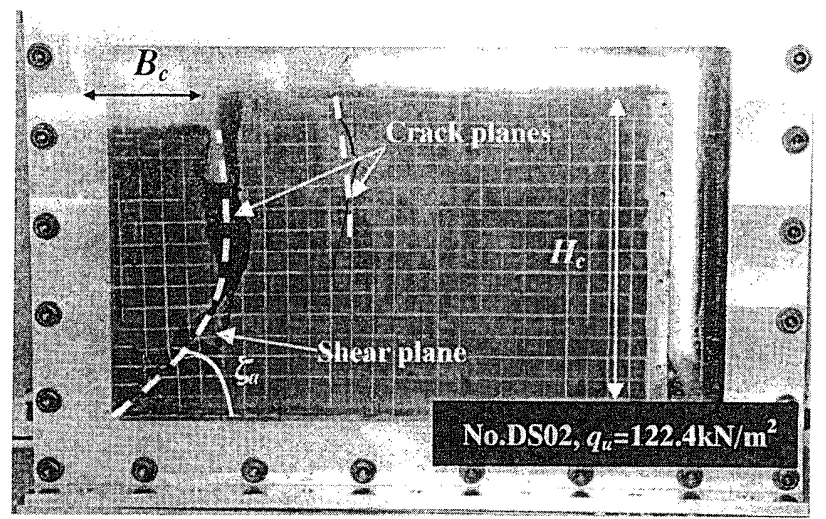

Fig. 10. Typical failure pattern of model ground in shaking test

against the centrifugal acceleration $G$ measured in the tilting test case No. PST14, where the corresponding horizontal seismic coefficient $k_{\mathrm{h}}$ is 0.25 . It can be seen that the $S$ value increases slightly at first as the $G$ increases but jumps up to around 25 to $35 \mathrm{~mm}$ due to ground failure just after $G$ reaches about $44 \mathrm{~g}$. This phenomenon indicates that the entire ground failure suddenly took place without serious effects of ground pre-failure progressive deformation. A typical failure pattern of the ground is shown in Fig. 9, which was obtained in the tilting test case No. PST11. For ease of detecting the failure pattern, the side surface of the model ground was painted as a grid pattern. In the figure, two tensile cracks developed almost perpendicular to the ground surface. But the visual observation during the centrifuge test showed that the tensile crack closer to the ground face (left hand side in the figure) took place first and another took place later. Two shear failure planes also developed from the bottom end of the tensile cracks toward the bottom of the ground base immediately after the tensile crack formed. A similar failure pattern was also found in the static condition of the cement treated fly ash ground (Kitazume, 1998). Figure 10 shows other failure pattern of the model ground observed in the shaking table test case No. DS02, where the model ground failed ultimately due to the input seismic excitation of the $73.6 \mathrm{gal}$ in a prototype scale. A couple of tensile crack planes and shear failure planes were often observed, not only in the titling tests, but also

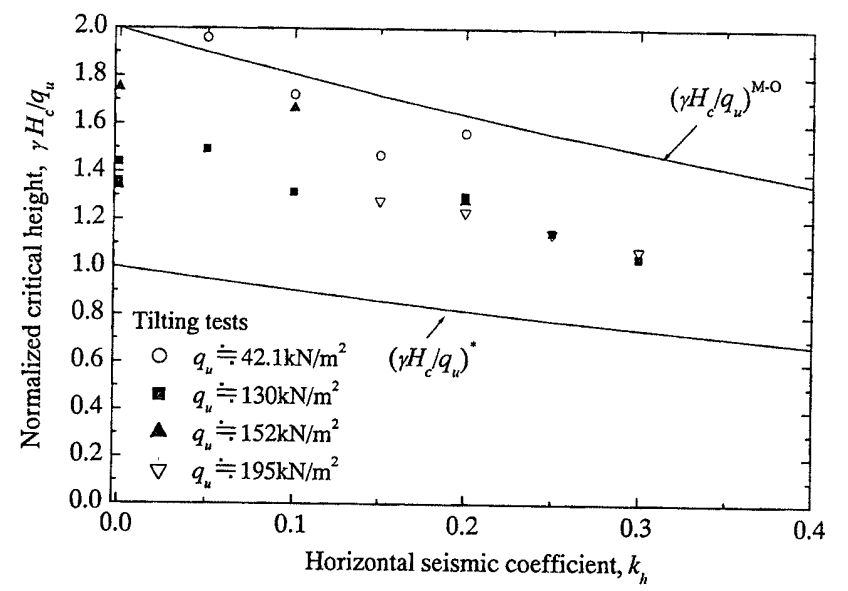

Fig. 11. The relationship between normalized critical height $\gamma H_{\mathrm{c}} / q_{\mathrm{u}}$ and horizontal seismic coefficient $k_{\mathrm{h}}$

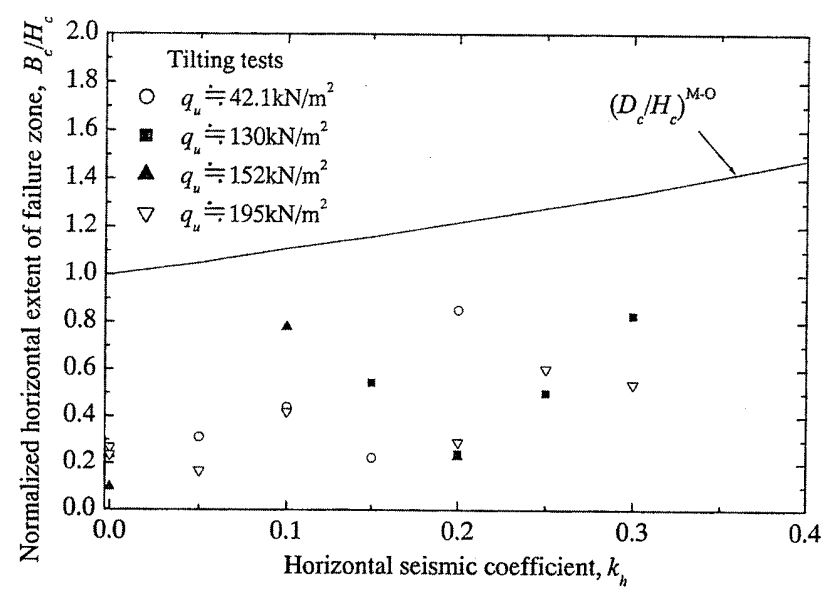

Fig. 12. The relationship between normalized horizontal extent of failure zone $B_{\mathrm{c}} / H_{\mathrm{c}}$ and horizontal seismic coefficient $\boldsymbol{k}_{\mathrm{h}}$

in the shaking table tests. However, the visual observation during the centrifuge test found that the tensile crack closet to the ground front face always took place first in the all test cases. These two figures show that the cement treated ground fails with a combination of shear and tensile failure planes irrespective of pseudo-static or dynamic test.

The failure pattern obtained in this study is much different from those of soft clayey ground or sandy ground (e.g. Japanese Soil Mechanics Society, 1994; Zeng, 1998). The features of the failure pattern is due to the considerably small ratio of tensile strength to compressive strength of the cement treated soil.

\section{DISCUSSION ON TILTING TESTS}

The value of centrifugal acceleration at ground failure, $G_{\mathrm{f}}$, was defined as the acceleration when the ground settlement jumped up as shown in Fig. 8. The $G_{\mathrm{f}}$ values thus obtained are summarized in Table 1 together with the test condition. The critical height $H_{\mathrm{c}}$ of the ground having an unsupported vertical slope is calculated by multiplying the height of the model ground and the $G_{\mathrm{f}}$. 

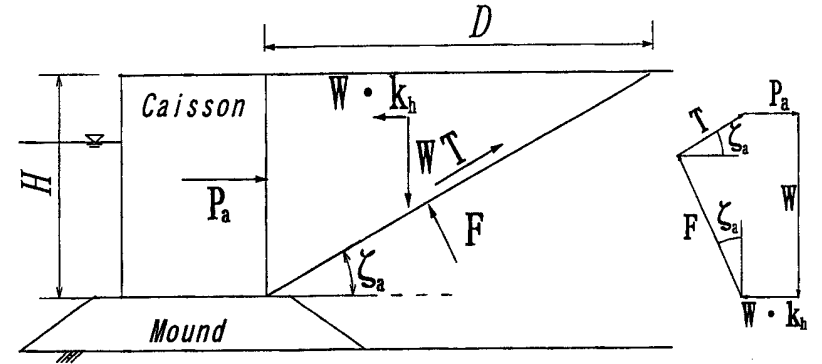

Fig. 13. Assumed failure block in the conventional pseudo-static limit equilibrium method

The normalized critical height $\gamma H_{\mathrm{c}} / q_{\mathrm{u}}$ is plotted against the horizontal seismic coefficient, $k_{\mathrm{h}}$ in Fig. 11, where $\gamma$ and $q_{\mathrm{u}}$ are the unit weight and the unconfined compressive strength of the model ground, respectively. The unconfined compressive strength, $q_{\mathrm{u}}$ is used here for normalizing instead of triaxial compressive strength, because the undrained peak strength is thought to be insensitive to initial confining pressure if the specimen is quasi-overconsolidated (Tatsuoka et al., 1983). Although there is a scatter in the measured data, it is found that the measured $\gamma H_{\mathrm{c}} / q_{\mathrm{u}}$ value decreases gradually with the increase of $k_{\mathrm{h}}$. Also, the $\gamma H_{\mathrm{c}} / q_{\mathrm{u}} \sim k_{\mathrm{h}}$ relationship is somewhat unique irrespective of the $q_{\mathrm{u}}$ values, except for the ground of $q_{\mathrm{u}} \fallingdotseq$ $42.1 \mathrm{kN} / \mathrm{m}^{2}\left(a_{\mathrm{w}}=6 \%\right)$. In Fig. 12, a normalized failure zone $B_{\mathrm{c}} / H_{\mathrm{c}}$ is plotted against $k_{\mathrm{h}}$, where $B_{\mathrm{c}}$ is the horizontal distance of the tensile crack plane measured from the front face of the ground at the ground surface. As several tensile crack planes were observed in the test as exemplified in Figs. 9 and 10, $B_{\mathrm{c}}$ is defined for the crack plane that takes place first. Although there is much scatter in the test data, it can be seen that the $B_{\mathrm{c}} / H_{\mathrm{c}}$ value increases slightly with the increase of $k_{\mathrm{h}}$ irrespective of the ground strength.

\section{A Conventional Pseudo-Static Limit Equilibrium Method}

The pseudo-static limit equilibrium method, Mononobe-Okabe's method, has been frequently applied in seismic design to evaluate the dynamic active earth pressure to retaining wall and sea revetment. In the method, the force equilibrium at the limit state for cohesive soil is examined on an assumed triangle soil block as shown in Fig. 13, provided that no friction is mobilized at the interface between the retaining wall and backfill soil. The following equations are given from the force equilibrium.

$$
\begin{aligned}
& P=W \cdot k_{\mathrm{h}}+F \sin \zeta-T \cos \zeta \\
& W=T \sin \zeta+F \cos \zeta
\end{aligned}
$$

where,

$P$ : dynamic resultant earth pressure

$W$ : weight of soil mass

$T$ : shear strength mobilizing along the shear plane

$F$ : reaction force perpendicular to the shear failure plane

$k_{\mathrm{h}}$ : horizontal seismic coefficient

$\zeta:$ inclination angle of the shear failure plane

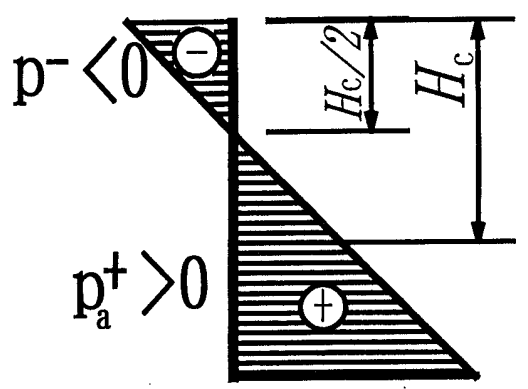

Fig. 14. Schematic view of active earth pressure distribution of a cohesive soil mass acting on a retaining a structure

Then, $P$ is given by,

$$
P=W \cdot k_{\mathrm{h}}+\frac{\sin \zeta}{\cos \zeta}(W-T \sin \zeta)-T \cos \zeta
$$

Here, $W$ and $T$ can be expressed as,

$$
\begin{aligned}
& W=\frac{1}{2} \frac{H^{2}}{\tan \zeta} \cdot \gamma \\
& T=\frac{H}{\sin \zeta} \cdot c_{\mathrm{u}}
\end{aligned}
$$

where,

$\gamma$ : unit weight of soil mass

$H$ : ground height

$c_{\mathrm{u}}$ : undrained shear strength

The resultant dynamic active earth pressure $P_{\mathrm{a}}$ is obtained by the following equation as the maximum value by changing the angle of the straight shear plane, $\zeta$, in the figure.

$$
P_{\mathrm{a}}=\left(1+\frac{k_{\mathrm{h}}}{\tan \zeta_{\mathrm{a}}}\right) \cdot \frac{\gamma}{2} \cdot H^{2}-c_{\mathrm{u}} \cdot H \cdot\left(\tan \zeta_{\mathrm{a}}+\frac{1}{\tan \zeta_{\mathrm{a}}}\right)
$$

where

$P_{\mathrm{a}}:$ dynamic resultant active earth pressure

$\zeta_{\mathrm{a}}\left(=\tan ^{-1}\left(\sqrt{1-\frac{\gamma H}{q_{\mathrm{u}}} k_{\mathrm{h}}}\right)\right)$

angle of shear failure plane at active condition

It is obvious that the $P_{\text {a }}$ value calculated in the equation becomes negative if the ground undrained shear strength, $q_{\mathrm{u}}$, becomes large and/or the ground height becomes small. In the same way, the $P_{\mathrm{a}}$ value in the MononobeOkabe's method is a sum up of negative earth pressure $p_{\mathrm{a}}^{-}$ at the shallower portion and positive earth pressure $p_{\mathrm{a}}^{+}$at the deeper portion.

The normalized critical height of the model ground based on Mononobe-Okabe's method, $\left(\gamma H_{\mathrm{c}} / q_{\mathrm{u}}\right)^{\mathrm{M}-\mathrm{O}}$ can be calculated by substituting zero for $P_{\mathrm{a}}$ in Eq. (6) and is plotted as a solid line in Fig. 11. It is found that the calculated $\left(\gamma H_{\mathrm{c}} / q_{\mathrm{u}}\right)^{\mathrm{M}-\mathrm{O}}$ value decreases almost linearly with the increase of $k_{\mathrm{h}}$ but is considerably larger than that of the tilting test results. This is because the failure pattern assumed in the Mononobe-Okabe's method, a straight shear failure plane alone, is much different from that obtained in the tests. The other reason is the overestimation of the effect of the negative earth pressure $p_{a}^{-}$mobilized at 

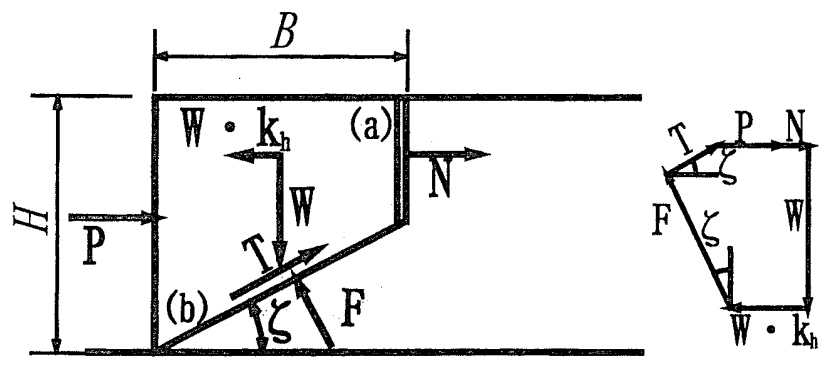

Fig. 15. Assumed failure block in the modified pseudo-static limit equilibrium method

the shallow depth as schematically shown in Fig. 14. In practical design, the effect of $p_{\mathrm{a}}^{-}$is sometimes neglected by setting $p_{\mathrm{a}}^{-}$equal to zero to obtain the normalized critical height, $\left(\gamma H_{\mathrm{c}} / q_{\mathrm{u}}\right)^{*}$. The $\left(\gamma H_{\mathrm{c}} / q_{\mathrm{u}}\right)^{*}$ is half of $\left(\gamma H_{\mathrm{c}} /\right.$ $\left.q_{\mathrm{u}}\right)^{\mathrm{M}-\mathrm{O}}$ and also plotted as a solid line in Fig. 11. It is found that $\left(\gamma H_{\mathrm{c}} / q_{\mathrm{u}}\right)^{*}$ is quite smaller than the test results. In the Mononobe-Okabe's method, the horizontal extent of the failure zone $D_{\mathrm{c}}$ at the ground surface of the unsupported ground is given by $H_{\mathrm{c}}$ and $\zeta_{\mathrm{a}}$ as the following equations:

$$
D_{\mathrm{c}}=H_{\mathrm{c}} / \tan \zeta_{\mathrm{a}}
$$

where

$$
\zeta_{\mathrm{a}}=\tan ^{-1}\left(\sqrt{1-\frac{\gamma H_{\mathrm{c}}}{q_{\mathrm{u}}} k_{\mathrm{h}}}\right)
$$

The normalized horizontal extent of the failure zone, $\left(D_{\mathrm{c}} / H_{\mathrm{c}}\right)^{\mathrm{M}-\mathrm{O}}$ is plotted as a solid line in Fig. 12. Figure 12 clearly shows that the calculated value is quite larger than the tilting test results. These differences suggest that the conventional pseudo-static limit equilibrium method cannot evaluate the earth pressure and the failure zone of the cement treated ground simultaneously.

\section{A Modified Pseudo-Static Limit Equilibrium Method}

A modified pseudo-static limit equilibrium method is proposed here, which incorporates the effect of the tensile force at the crack plane. Based on the failure pattern of the treated ground as shown in Figs. 9 and 10, the trapezoid soil block is assumed in the method, as shown in Fig. 15, whose boundaries are defined by a tensile crack (a) and a shear failure plane (b). Equations (8) and (9) are obtained by satisfying the horizontal and vertical force equilibriums on the soil block.

$$
\begin{aligned}
& P=W \cdot k_{\mathrm{h}}+F \sin \zeta-T \cos \zeta-N \\
& W=T \sin \zeta+F \cos \zeta
\end{aligned}
$$

where,

$P$ : resultant dynamic earth pressure

$W$ : weight of soil block

$F$ : reaction force perpendicular to the shear failure plane

$N:$ total tensile force on the tensile crack plane

$k_{\mathrm{h}}$ : horizontal seismic coefficient

$T$ : shear strength mobilizing along the shear failure plane $\zeta:$ inclination angle of the shear failure plane

$B$ : horizontal distance of the tensile crack from the front face of the ground

After substituting Eq. (9) into Eq. (8), $P$ is given by:

$$
P=W \cdot k_{\mathrm{h}}+\frac{\sin \zeta}{\cos \zeta}(W-T \sin \zeta)-T \cos \zeta-N
$$

Here, $W, T$ and $N$ can be expressed as,

$$
\begin{aligned}
& W=(2 H-B \tan \zeta) \cdot \frac{B}{2} \cdot \gamma \\
& T=\beta\left(\frac{q_{\mathrm{u}}}{2}\right) \cdot \frac{B}{\cos \zeta} \\
& N=\left(\alpha q_{\mathrm{u}}\right) \cdot(H-B \tan \zeta)
\end{aligned}
$$

where,

$q_{\mathrm{u}}$ : unconfined compressive strength of ground

$\alpha$ : ratio of tensile strength to $q_{\mathrm{u}}$ of ground

$\beta$ : mobilization degree of $q_{\mathrm{u}}$ on the boundary (b)

$\gamma$ : unit weight of ground

Here a parameter, $\beta$, is introduced to incorporate the progressive failure phenomenon along the shear failure plane. The value of $\beta$ is 1 for full mobilization of shear strength along the failure plane, while it is less than 1 for partial mobilization. Substituting $W, T$ and $N$ into Eq. (10) followed by normalization for plane strain condition with respect to $\gamma H^{2} / 2$, the resultant dynamic earth pressure coefficient, $K$ is given by:

$$
\begin{aligned}
K= & \frac{P}{\gamma H^{2} / 2} \\
= & -2 \alpha\left(1-\frac{B}{H} x\right) \frac{q_{\mathrm{u}}}{\gamma H}-\beta\left(1+x^{2}\right)\left(\frac{B}{H}\right) \frac{q_{\mathrm{u}}}{\gamma H} \\
& +2\left(k_{\mathrm{h}}+x\right) \frac{B}{H}-\left(k_{\mathrm{h}} \cdot x+x^{2}\right)\left(\frac{B}{H}\right)^{2}
\end{aligned}
$$

where

$$
x=\tan \zeta
$$

In order to obtain the maximum or minimum $K$ value for the given $\gamma, q_{\mathrm{u}}$ and $H$ values, Eq. (14) is differentiated with respect to $B / H$ or $x$ and is set to equal zero respectively,

$$
\begin{gathered}
\frac{\partial K}{\partial x}=2 \alpha\left(\frac{B}{H}\right) \frac{q_{\mathrm{u}}}{r H}-2 \beta x\left(\frac{B}{H}\right) \frac{q_{\mathrm{u}}}{r H}+2\left(\frac{B}{H}\right) \\
-\left(k_{\mathrm{h}}+2 x\right)\left(\frac{B}{H}\right)^{2}=0 \\
\therefore x=\frac{2 \alpha \frac{q_{\mathrm{u}}}{r H}+2-k_{\mathrm{h}} \frac{B}{H}}{2\left(\beta \frac{q_{\mathrm{u}}}{r H}+\frac{B}{H}\right)}=\frac{\alpha \frac{q_{\mathrm{u}}}{r H}+1-\frac{k_{\mathrm{h}}}{2} \frac{B}{H}}{\beta \frac{q_{\mathrm{u}}}{r H}+\frac{B}{H}} \\
\frac{\partial K}{\partial B / H}=2 \alpha \cdot x \frac{q_{\mathrm{u}}}{\gamma H}-\beta\left(1+x^{2}\right) \frac{q_{\mathrm{u}}}{\gamma H}+2\left(k_{\mathrm{h}} x+x\right) \\
-2\left(k_{\mathrm{h}} \cdot x+x^{2}\right)\left(\frac{B}{H}\right)=0
\end{gathered}
$$


$\therefore \frac{B}{H}=\frac{2 \alpha \cdot x \frac{q_{\mathrm{u}}}{\gamma H}-\beta\left(1+x^{2}\right) \frac{q_{\mathrm{u}}}{\gamma H}+2\left(k_{\mathrm{h}}+x\right)}{2\left(k_{\mathrm{h}} \cdot x+x^{2}\right)}$

After substituting Eq. (17) into Eq. (16), a cubic equation with respect to $x$ is obtained as follows

$$
\begin{aligned}
\therefore & x^{3}+\frac{3}{2} k_{\mathrm{h}} x^{2}+\left(\frac{k_{\mathrm{h}}}{\beta q_{\mathrm{u}} / \gamma H}-\frac{\alpha}{\beta} k_{\mathrm{h}}-1\right) x \\
& +\frac{k_{\mathrm{h}}^{2}}{\beta \cdot q_{\mathrm{u}} / \gamma H}-\frac{k_{\mathrm{h}}}{2}=0
\end{aligned}
$$

In the case of $k_{\mathrm{h}}=0$, which is the static condition, Eq. (18) becomes a simple expression as the following equation:

$$
\therefore x^{3}-x=0
$$

$x=\tan \zeta$ of 1 is obtained as a significant solution. This means that the inclination angle of the shear failure plane, $\zeta$, is always 45 degrees for the static condition irrespective of the strength and unit weight of the ground. In the case of the dynamic condition, where $k_{\mathrm{h}}$ is not zero, three solutions named as $x_{1}, x_{2}, x_{3}$ of the cubic equation are obtained by Cardano's formula. The three solutions are either three real numbers or one real and two imaginary numbers. The meaningful solution for this study should be a real number and positive value. On the assumption that active failure tends to occur when $K$ value becomes maximum, the resultant dynamic active earth pressure coefficient, $K_{\mathrm{a}}$, can be obtained when the solution $x$ satisfies the following condition (strictly speaking, when $C_{1}$ of Eq. (19) equals zero, another condition derived from higher degrees of differential equations should be satisfied),

$$
C_{1}=\frac{\partial^{2} K}{\partial x^{2}} \cdot \frac{\partial^{2} K}{\partial(B / H)^{2}}-\frac{\partial^{2} K}{\partial x \partial(B / H)}>0
$$

and

$$
C_{2}=\frac{\partial^{2} K}{\partial x^{2}}<0
$$

In Eq. (19), $x$ and $B / H$ should be larger than zero to produce positive values of $\zeta_{\mathrm{a}}$ and $B_{\mathrm{a}}$, those are $\zeta$ and $B$ at active failure condition respectively. After the solution $x$ is calculated in Eqs. (18) and (19), the corresponding $\zeta_{\mathrm{a}}$, $B_{\mathrm{a}}$ and $K_{\mathrm{a}}$ are calculated in Eqs. (15), (17) and (14).

By setting $K$ to zero in Eq. (14), then the following equation is derived:

$$
\therefore H=\frac{q_{\mathrm{u}}}{\gamma} \cdot \frac{2 \alpha\left\{1-\left(\frac{B}{H}\right) x\right\}+\beta\left(1+x^{2}\right)\left(\frac{B}{H}\right)}{2\left(k_{\mathrm{h}}+x\right)\left(\frac{B}{H}\right)-\left(k_{\mathrm{h}} \cdot x+x^{2}\right)\left(\frac{B}{H}\right)^{2}}
$$

When $x$ and $B / H$ obtained for a given $H$ satisfy Eq. (20), $H$ corresponds to the critical height of unsupported ground, $H_{\mathrm{c}}$. The $H_{\mathrm{c}}$ value can be numerically determined for a given condition. Hereafter, the horizontal distance of the tensile crack measured from the front face, $B$, at the critical height is referred as $B_{\mathrm{c}}$. It is found in Eqs. (20) and (17) that the values of $H_{\mathrm{c}}$ and $B_{\mathrm{c}} / H_{\mathrm{c}}$ are influenced by

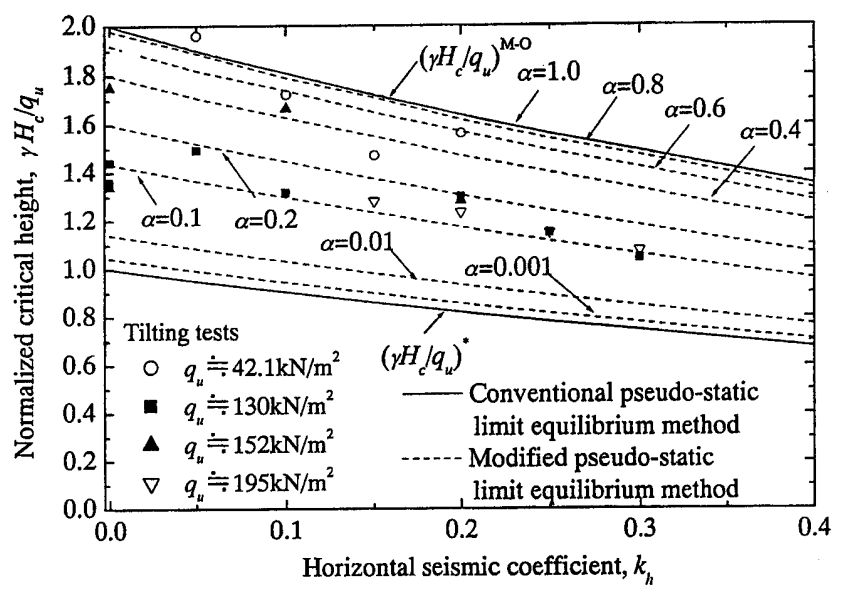

Fig. 16. The relationship between normalized critical height $\gamma H_{\mathrm{c}} / q_{\mathrm{u}}$ and horizontal seismic coefficient $\boldsymbol{k}_{\mathrm{h}}$

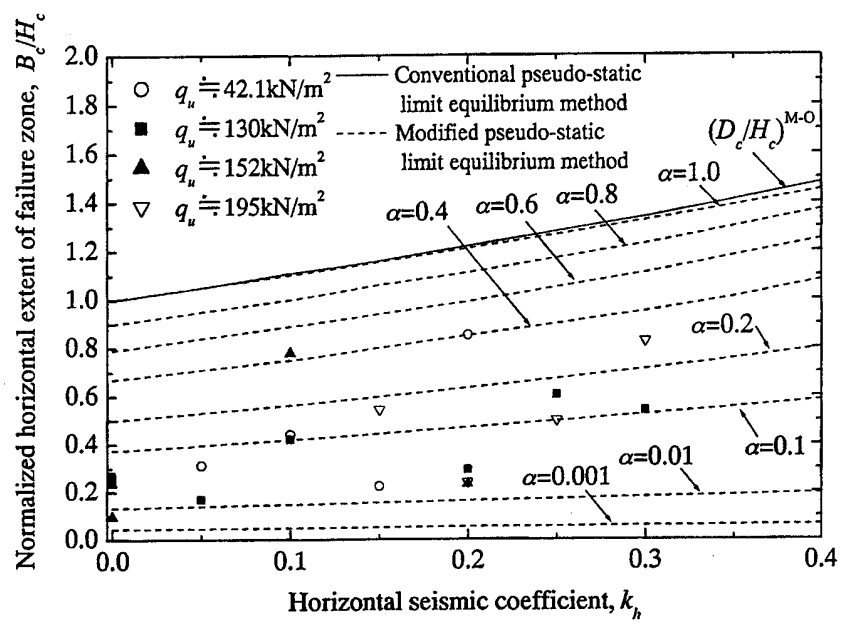

Fig. 17. The relationship between normalized horizontal extent of failure zone $B_{\mathrm{c}} / H_{\mathrm{c}}$ and horizontal seismic coefficient, $\boldsymbol{k}_{\mathrm{h}}$

two parameters $\alpha$ and $\beta$, as well as $k_{\mathrm{h}}$. Again, $\beta$, is a parameter to incorporate the progressive failure phenomenon along the shear failure plane. Its value is equal to or less than 1 for mobilization degree of shear strength. Here the value of $\beta$ is assumed to be 1 , because the shear plane of the model ground develops very rapidly while a small amount of $G$ increases as already discussed in Fig. 8.

The normalized critical height $\gamma H_{\mathrm{c}} / q_{\mathrm{u}}$ calculated from Eq. (20) for various $\alpha$ values are plotted against $k_{\mathrm{h}}$ in Fig. 16, together with the tilting test results. It is found that the calculated values of $\gamma H_{\mathrm{c}} / q_{\mathrm{u}}$ are highly dependent on the $\alpha$ value, and decrease with the increase of $k_{\mathrm{h}}$ irrespective of the $\alpha$ value. It is of interest that the $\gamma H_{\mathrm{c}} / q_{\mathrm{u}}$ values for $\alpha=1$ and $\alpha \fallingdotseq 0$ almost coincide to $\left(\gamma H_{\mathrm{c}} / q_{\mathrm{u}}\right)^{\mathrm{M}-\mathrm{O}}$ and $\left(\gamma H_{\mathrm{c}} / q_{\mathrm{u}}\right)^{*}$ respectively. This indicates that the modified method is a more general formula for the failure mechanism of the ground and includes the conventional pseudo-static limit equilibrium method. The figure shows that the test results can be reasonably explained by the modified method with the $\alpha$ value ranging from 0.1 to 0.2 , which is quite close to the $\sigma_{\mathrm{st}} / q_{\mathrm{u}}$ value obtained in the 

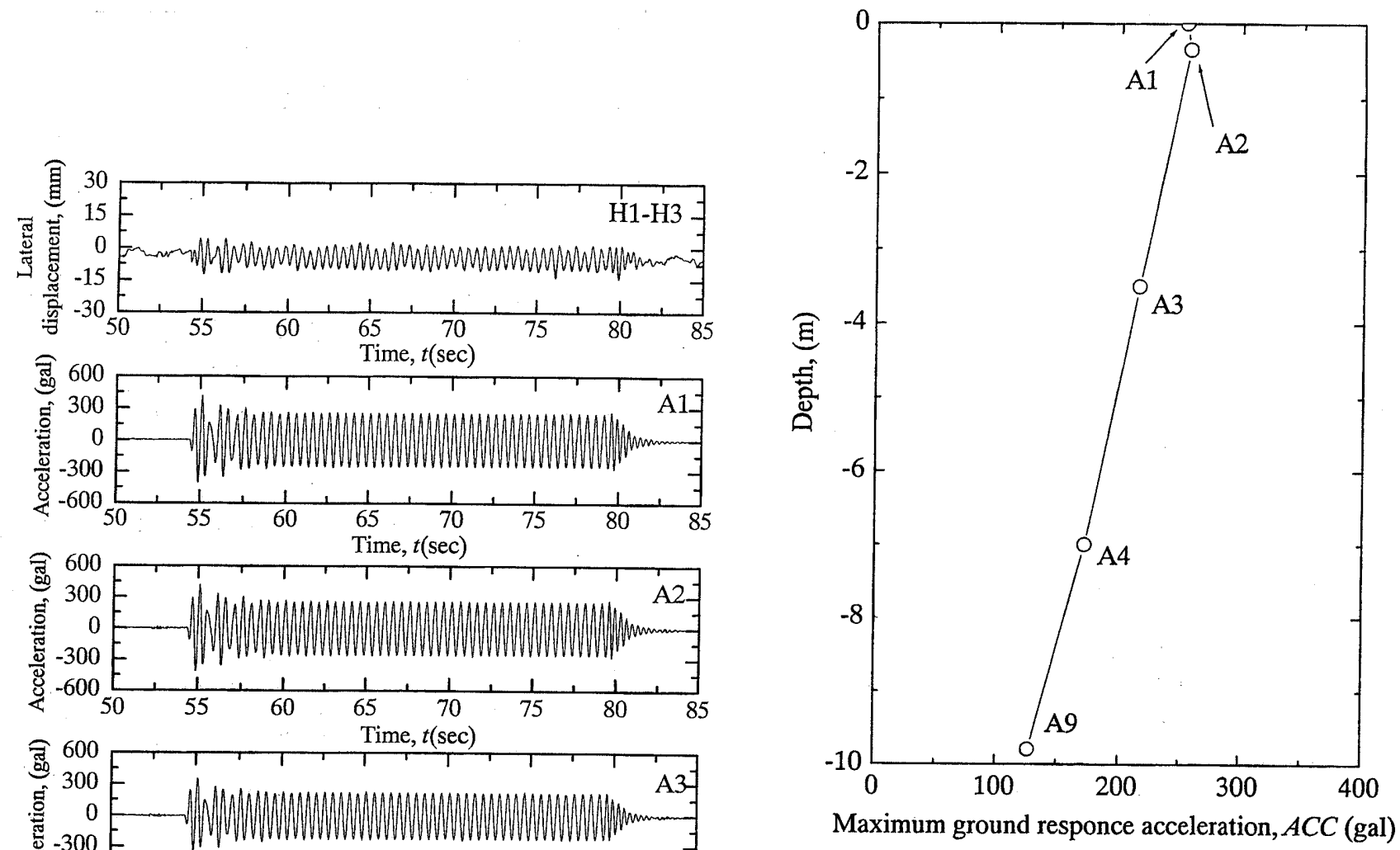

(b)

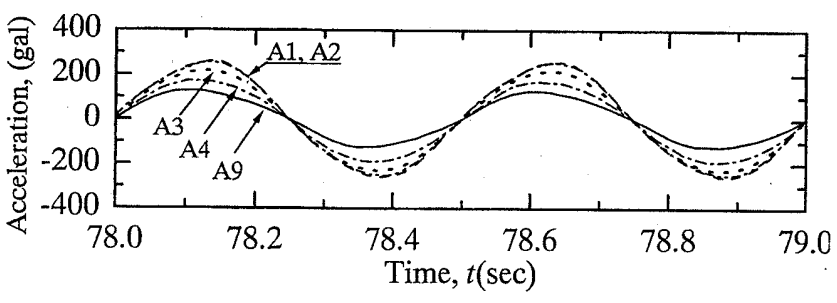

(c)

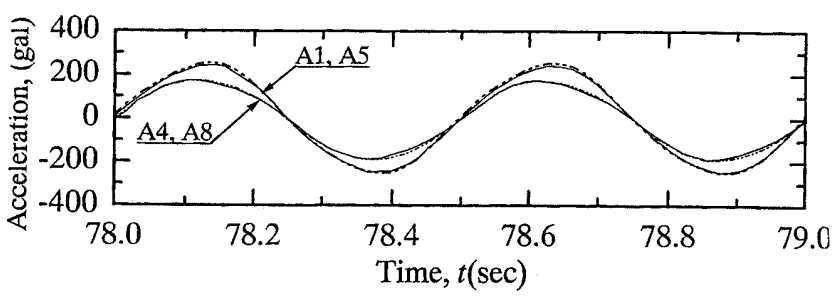

(d)

Fig. 18. (a) Time histories of ground displacement and accelerations during shaking test, (b) The relationship between maximum ground acceleration and depth, (c) Comparison of ground response accelerations along the vertical plane and (d) Comparison of ground response accelerations along the horizontal plane

split tests as shown in Fig. 7. In Fig. 17, the normalized horizontal extent of the failure zone $B_{\mathrm{c}} / H_{\mathrm{c}}$ calculated from Eq. (17) is plotted against the $k_{\mathrm{h}}$. The $B_{\mathrm{c}} / H_{\mathrm{c}}$ value is also dependent on the $\alpha$, and slightly increases with the increase of $k_{\mathrm{h}}$ irrespective of the $\alpha$. The test results, although scattered, coincide well with the $B_{\mathrm{c}} / H_{\mathrm{c}}$ value calculated by the modified method with $\alpha$ less than 0.2 , as similar to the $\gamma H_{\mathrm{c}} / q_{\mathrm{u}} \sim k_{\mathrm{h}}$ relationship. It can be concluded that the modified method can give a reasonable evaluation of the critical height and the failure zone of the cement treated ground in the tilting tests if the ratio of tensile to compressive strengths of 0.1 to 0.2 is adopted.

\section{DISCUSSIONS ON SHAKING TABLE TESTS}

In this section, the dynamic response of the ground is discussed to confirm the findings in the pseudo-static approach. In the shaking table tests, the model ground was brought up to a high centrifuged acceleration field and then was subjected to dynamic excitation with 

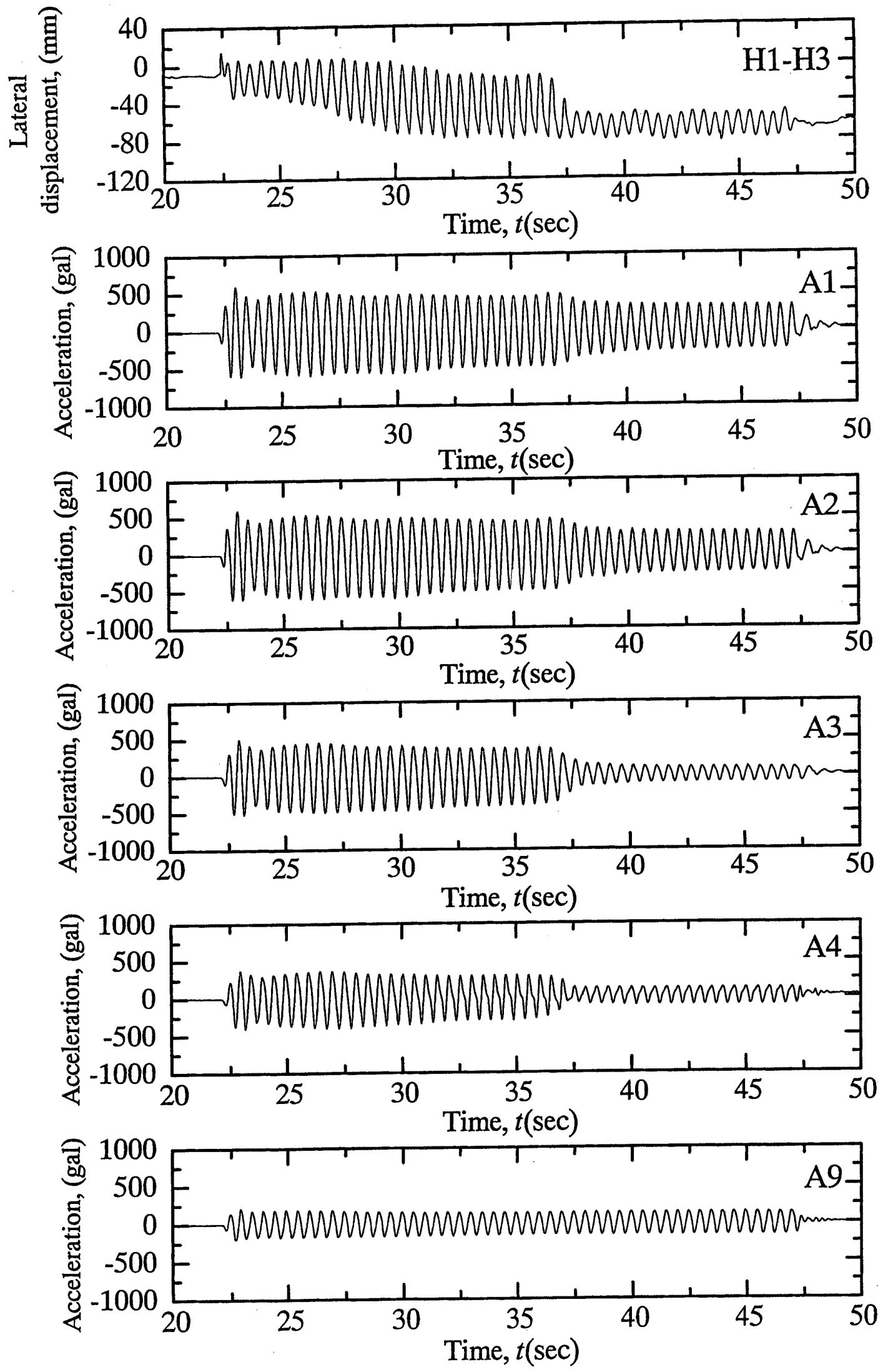

Fig. 19. Time histories of ground displacement and accelerations during shaking test 
sinusoidal waves at a frequency of $2 \mathrm{~Hz}$ in a prototype scale. The amplitude of the excitation was increased stepwise until the model ground failed. During each shaking step, the base acceleration, the ground response accelerations at various depths and the horizontal and vertical displacements of the ground were measured with transducers as already shown in Fig. 4.

\section{Ground Response Acceleration}

Figure 18(a) shows the measured time histories of the accelerations at various locations and the horizontal displacements at the ground surface in test case No. DS01. Those are converted into prototype scale. The amplitude of the base acceleration was measured with A9 accelerometer and about $125 \mathrm{gal}$. The horizontal displacement of the ground was calculated by subtracting the measured displacement with $\mathrm{H} 1$ from that with $\mathrm{H} 3$. It was found that the model ground was stable during and after the shaking with very small residual horizontal movement. Although the measured base acceleration wave was somewhat unstable in the first several cycles probably due to technical problems, it became stable and almost constant after the third cycle. The ground response accelerations measured with A1 through A4 also had unstable waves at first but became stable thereafter. It is found in the figure that the cement treated ground shows larger response rather than the base. The maximum accelerations, $A C C$, measured at various ground levels during the excitation are plotted in Fig. 18(b) with the depth. It is found that the maximum ground acceleration is amplified toward the ground surface. Figure 18(c)(d) shows a part of the response acceleration curves so closely that the ground response can be observed in detail. Figure 18(c) shows that the response acceleration along with depth. It is of interest that a small time difference of the response acceleration in the vertical direction of the model ground is observed while the responses in the horizontal direction are almost same as shown in Fig. 18(d). It can be thought that the response acceleration and the dynamic amplification is not uniform in the vertical direction, but uniform in the horizontal direction of the pre-failure model ground.

Figure 19 shows the other measured time histories of the base acceleration, the response accelerations and the displacement increment of the same model ground as shown in Fig. 18. The plotted data in Fig. 19 were measured during the eighth shaking stage when the ultimate failure was observed in the ground and converted into a prototype scale. It can be seen that the amplitude of horizontal displacement of the ground, $\mathrm{H} 1$ to $\mathrm{H} 3$, shows a relatively large value in the first phase of shaking but a small value after about $37 \mathrm{sec}$. And it is also found that a large residual displacement takes place after the shaking. It is clearly recognized in the measured acceleration response curves for A1 to A4 that the response accelerations of the ground suddenly decrease in amplitude at about $37 \mathrm{sec}$ on the time scale, when the amplitude of the horizontal displacement becomes small. This phenomenon suggests that the model ground starts to fail at that

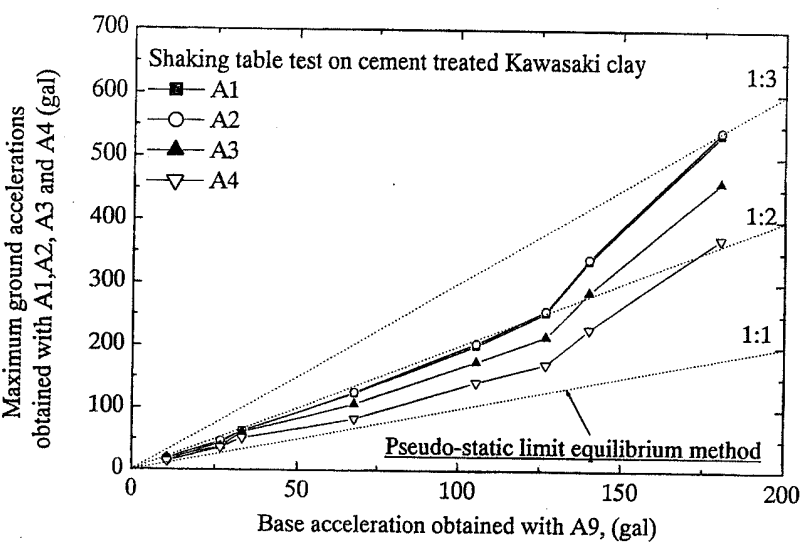

(a)

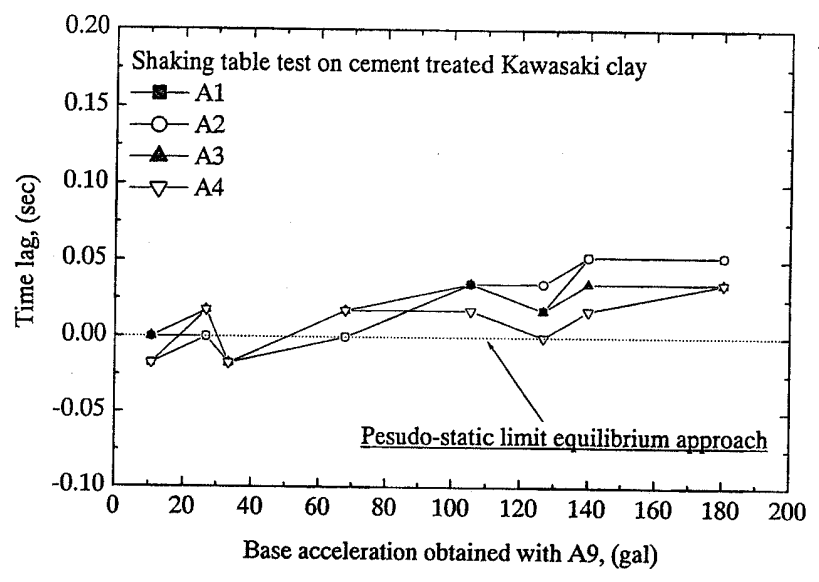

(b)

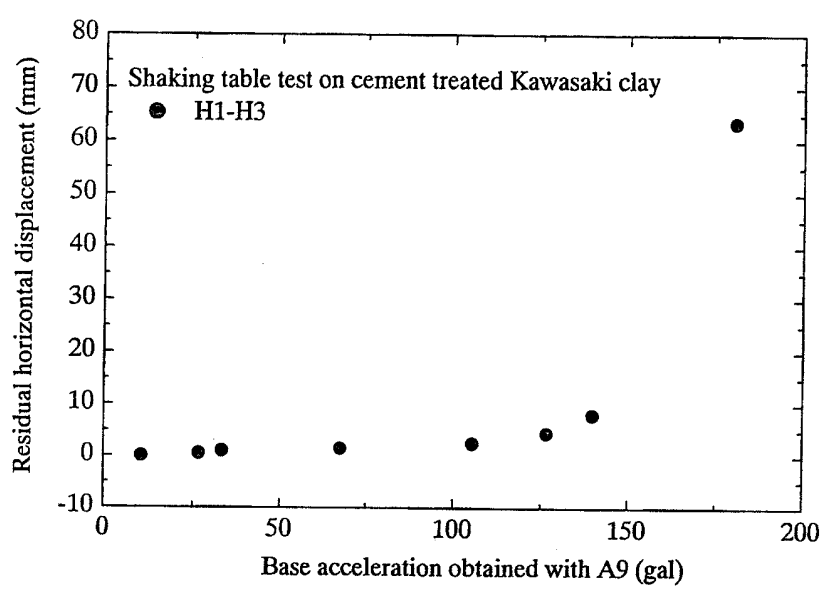

(c)

Fig. 20. (a) The relationship between maximum ground accelerations and base acceleration (test case No. DS01), (b) The relationship between time lags and base acceleration (test case No. DS01) and (c) The relationship between residual horizontal displacement and base acceleration (test case No. DS01)

time. It is also observed during the test that the tensile crack took place at first and was followed by the entire collapse with the development of a shear plane. 


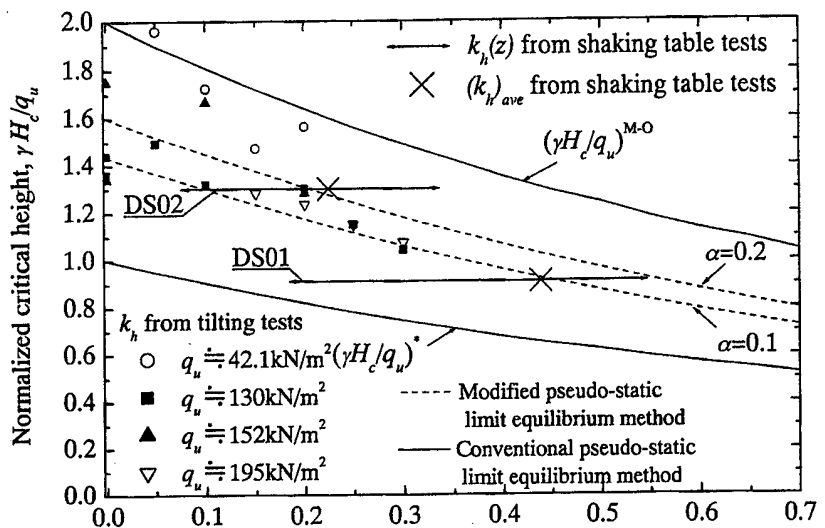

Fig. 21. The relationship between normalized critical height $\gamma H_{\mathrm{c}} / q_{\mathrm{u}}$ and horizontal seismic coefficient $k_{\mathrm{h}}, k_{\mathrm{h}}(z),\left(k_{\mathrm{h}}\right)_{\text {ave }}$

\section{Average $k_{h}$ Value Used in Modified Pseudo-Static Limit Equilibrium Method}

In Fig. 20(a), the maximum ground accelerations obtained with A1 through A4 are plotted against the base acceleration, which are obtained in each shaking stage in test case No. DS01. It is seen in Fig. 20(a) that the maximum accelerations at various ground levels are larger than the base acceleration. The response ratios at each location are almost constant from the first to the sixth shaking stages but increase after then when the model ground is close to failure. The time lags of the ground response behind the base accelerations are also plotted in Fig. 20(b). It is found that the time lags are quite small at the relatively small base acceleration but increase gradually with the increase of base acceleration. Figure 20(c) shows the accumulative horizontal displacement of the ground plotted against the base acceleration for each shaking step. Small horizontal displacement takes place with the increase of base acceleration, but the horizontal displacement rapidly increases when the ground is subjected to the critical acceleration.

In order to apply the pseudo-static method to the shaking table test results, the maximum ground accelerations, $A C C$, measured at various ground levels are focused on. Steedman and Zeng (1990) pointed out that amplification up through the soil layer had an important effect on the magnitude of dynamic earth pressure but phase change had negligible effect on the magnitude of the dynamic earth pressure. It is suggested that the effect of time lag within the soil block in Fig. 20(b) can be neglected. Based on this assumption, $A C C$ can be expressed as $A C C(z)$, which is a function of ground depth, $z$. Figure 21 shows the normalized critical height $\gamma H_{\mathrm{c}} / q_{\mathrm{u}}$ plotted against the horizontal seismic coefficient $k_{\mathrm{h}}(z)$, which is defined as $A C C(z) / 980_{\text {gal }}$ in two shaking table tests, together with the $\gamma H_{\mathrm{c}} / q_{\mathrm{u}} \sim k_{\mathrm{h}}$ relationships obtained in the tilting tests. In the figure, a range of $k_{\mathrm{h}}(z)$ values is shown as straight line with arrows at both ends. It is found that the $k_{\mathrm{h}}(z)$ has wide variation but is plotted inbetween the critical horizontal seismic coefficients based on the conventional pseudo-static limit equilibrium methods for the corresponding $\gamma H_{\mathrm{c}} / q_{\mathrm{u}}$. In order to discuss this more precisely,

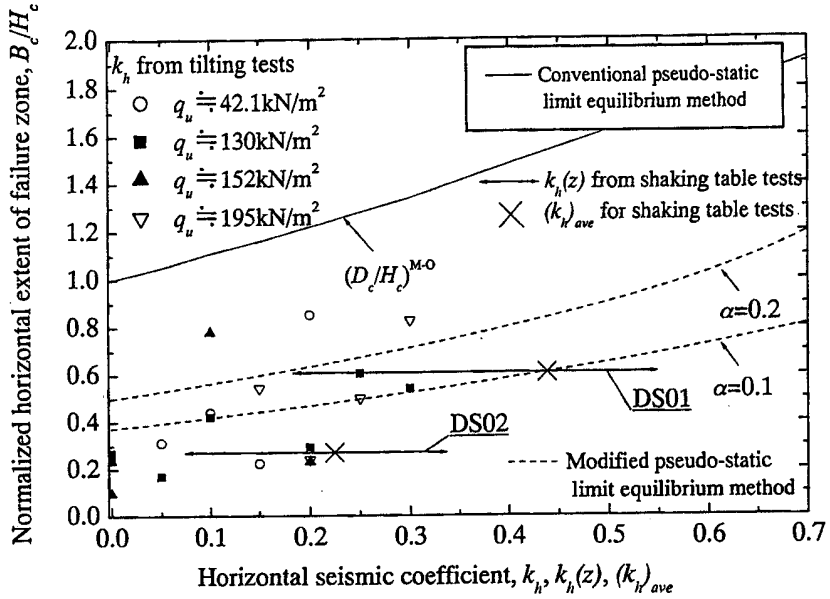

Fig. 22. The relationship between normalized horizontal extent of failure zone $B_{\mathrm{c}} / H_{\mathrm{c}}$ and horizontal seismic coefficient $k_{\mathrm{h}}, k_{\mathrm{h}}(z)$, $\left(k_{\mathrm{h}}\right)_{\text {ave }}$

the average horizontal inertia force is calculated by integrating the measured ground response acceleration $A c c(z)$ within the failure block as follows;

$$
\begin{aligned}
W \cdot\left(k_{\mathrm{h}}\right)_{\text {ave }}= & \int_{0}^{z_{\mathrm{c}}} \frac{A c c(z)}{g} \cdot \gamma \cdot B_{\mathrm{c}} d z \\
& +\int_{z_{\mathrm{e}}}^{H} \frac{A c c(z)}{g} \cdot \gamma \cdot\left\{B_{\mathrm{c}}-\frac{B_{\mathrm{c}}}{H_{\mathrm{c}}-z_{\mathrm{c}}}\left(z-z_{\mathrm{c}}\right)\right\} d z \\
= & \int_{0}^{z_{\mathrm{c}}} k_{\mathrm{h}}(z) \cdot \gamma \cdot B_{\mathrm{c}} d z \\
& +\int_{z_{\mathrm{c}}}^{H} k_{\mathrm{h}}(z) \cdot \gamma \cdot\left\{B_{\mathrm{c}}-\frac{B_{\mathrm{c}}}{H_{\mathrm{c}}-z_{\mathrm{c}}}\left(z-z_{\mathrm{c}}\right)\right\} d z(21)
\end{aligned}
$$

where $W$ is the weight of the trapezoid soil block and can be estimated from test results. And $z_{\mathrm{c}}$ is the depth of the tensile crack measured from the ground surface. In Eq. (21), the average inertia force $W \cdot\left(k_{\mathrm{h}}\right)_{\text {ave }}$ is numerically calculated from the test results with an assumption of the linear distribution of $k_{\mathrm{h}}(z)$ within the soil block (see Fig. 18(b)). Then the average horizontal seismic coefficient $\left(k_{\mathrm{h}}\right)_{\text {ave }}$ value can be obtained and is plotted as a cross mark in Fig. 20. It is found that the $\gamma H_{\mathrm{c}} / q_{\mathrm{u}} \sim\left(k_{\mathrm{h}}\right)_{\text {ave }}$ relationships are very similar to the $\gamma H_{\mathrm{c}} / q_{\mathrm{u}} \sim k_{\mathrm{h}}$ relationships obtained in tilting tests and are close to that based on the modified pseudo-static limit equilibrium method for $\alpha$ in the range from 0.1 to 0.2 . Figure 22 shows the relationships between the normalized horizontal extent of the failure zone $B_{\mathrm{c}} / H_{\mathrm{c}}$ and $k_{\mathrm{h}}(z),\left(k_{\mathrm{h}}\right)_{\text {ave }}$. As no tensile crack plane is incorporated in the conventional pseudostatic method, $D_{\mathrm{c}} / H_{\mathrm{c}}$ is plotted in the figure in which $D_{\mathrm{c}}$ is the horizontal distance of the triangular failure zone as shown in Fig. 13. In the figure, the test data obtained in the tilting tests and the shaking table tests are also plotted. It is seen that the conventional pseudo-static method overestimates the $B_{\mathrm{c}} / H_{\mathrm{c}}$ values obtained in the shaking tests as well as those in the tilting tests. However, it is found that the $B_{\mathrm{c}} / H_{\mathrm{c}} \sim k_{\mathrm{h}}$ relationships calculated by the modified method with the $\alpha$ ranging from 0.1 to 0.2 are relatively close to the test data in the tilting tests and the shaking table tests No. DS01. The $B_{\mathrm{c}} / H_{\mathrm{c}}$ value obtained 


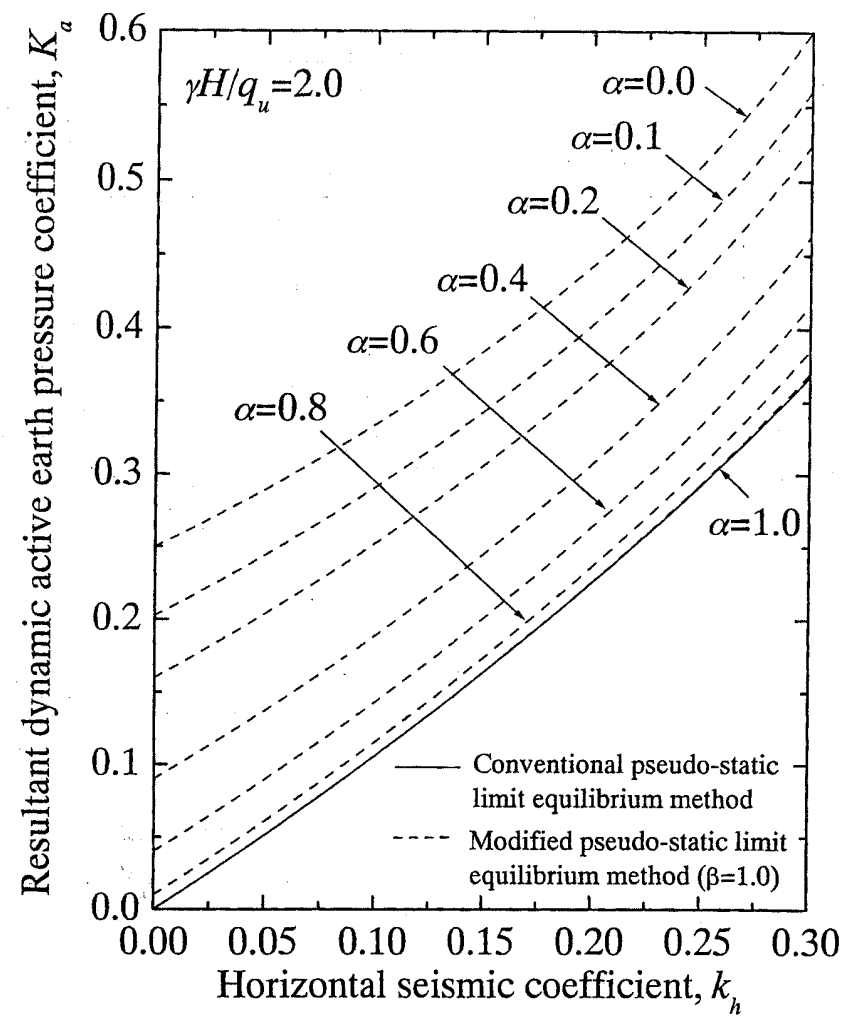

Fig. 23. The relationship between resultant seismic active coefficient, $K_{\mathrm{a}}$ and horizontal seismic coefficient $\boldsymbol{k}_{\mathrm{h}}$, calculated by conventional and modified pseudo-static limit equilibrium methods

in the test case No. DS02 is within the range of the test data in the tilting test but more or less smaller than that of the modified method with the $\alpha$ ranging from 0.1 to 0.2 . This difference might be due to some effect of the failure pattern in which two tensile cracks developed almost simultaneously in the test case No. DS02. But further study is required to investigate the difference more precisely. It can be concluded that the modified pseudo-static limit equilibrium method can properly evaluate the seismic stability of the cement treated ground subjected to dynamic excitations provided that the average horizontal seismic coefficient $\left(k_{\mathrm{h}}\right)_{\text {ave }}$ is calculated precisely as described above. In the modified method, the effect of progressive or dynamic accumulative deformation is not considered. However, the effect is thought to be small according to previous research, for example by Kokusho et al. (2001), which shows that cement treated kaolinite clay has its original undrained strength even after cyclic loading with high stress amplitude while the deformation modulus tends to decrease with the increase of cyclic loading amplitude. However, further research is required to investigate the effect in more detail.

\section{DISCUSSIONS ON DYNAMIC ACTIVE EARTH PRESSURE}

In the previous session, the critical height of the cement treated ground is discussed to focus on the effect of the failure pattern. Here, the dynamic earth pressure of the cement treated ground is discussed through focusing on

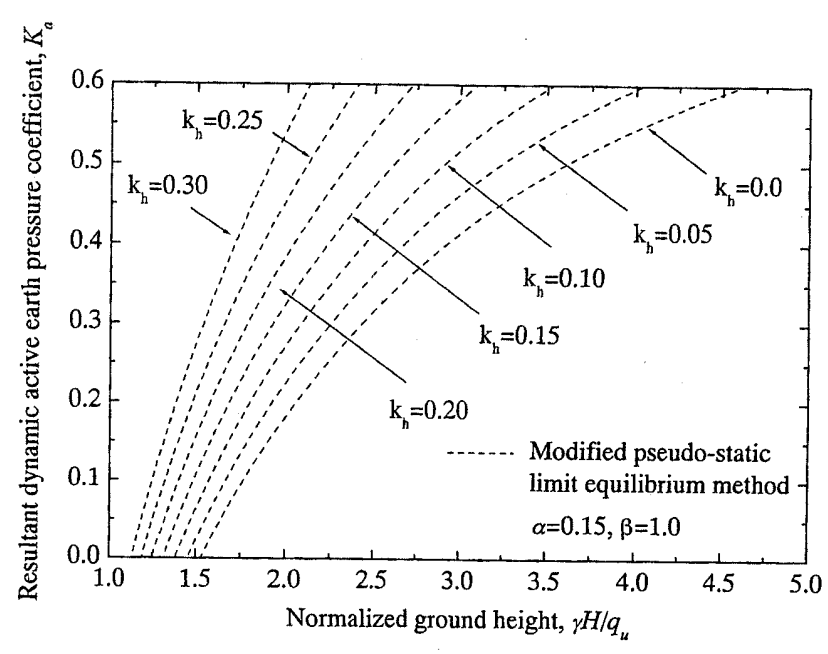

Fig. 24. The relationship between $K_{\mathrm{a}}$ and $k_{\mathrm{h}}$ calculated by conventional and modified pseudo-static limit equilibrium methods

this effect. The dynamic active earth pressure $P_{\text {a }}$ can be obtained through Eqs. (6) and (14) for the conventional and modified pseudo-static limit equilibrium methods respectively. Then, the resultant seismic active coefficient, $K_{\mathrm{a}}$ is obtained from $P_{\mathrm{a}}$ divided by $\gamma H^{2} / 2$ and is shown in Fig. 23 against the $k_{\mathrm{h}}$ value in the case of the normalized height $\gamma H / q_{u}$ of 2.0 and $\beta$ of 1 . In the figure, the calculated values by the modified pseudo-static equilibrium method with $\alpha$ ranging from 0.0 to 1.0 are plotted together with the conventional pseudo-static limit equilibrium method. It is found that $K_{\mathrm{a}}$ highly depends on the $\alpha$ value and increases with decreasing the $\alpha$ value. It is of interest that the $K_{\mathrm{a}}$ obtained from the conventional pseudo-static limit equilibrium method is quite close to that obtained by the modified method with $\alpha=1$.

To discuss the effects of the normalized ground height $\gamma H / q_{\mathrm{u}}$ on the $K_{\mathrm{a}}$ in the modified pseudo-static limit equilibrium method, the relationship between $P_{\mathrm{a}}$ and $\gamma H /$ $q_{\mathrm{u}}$ is calculated in Eq. (14) for various $k_{\mathrm{h}}$ values in the case of an $\alpha$ of 0.15 . The relationships between $K_{\mathrm{a}}$ and $\gamma H / q_{\mathrm{u}}$ are plotted in Fig. 24. It is seen that $K_{\mathrm{a}}$ increases rapidly with increase of $\gamma H / q_{\mathrm{u}}$ when $k_{\mathrm{h}}$ becomes larger.

As the dynamic active earth pressure of the ground is much dependent upon the interaction between the retaining wall and the ground during excitation, the calculated earth pressure by the modified method should be verified by model tests and/or field measurements. But these results emphasize the importance of incorporating the failure pattern of the ground for evaluating the earth pressure and the critical height of the cement treated clay ground.

\section{CONCLUSIONS}

A series of tilting tests and shaking table tests was conducted on a geotechnical centrifuge apparatus to investigate the seismic stability of cement treated ground having an unsupported vertical slope. Both of the test results show the unique feature of failure pattern that is 
characterized by a combination of a vertical tension crack and a shear failure plane.

The conventional pseudo-static limit equilibrium method based on Mononobe-Okabe's earth pressure theory is applied to evaluate the seismic stability of the ground obtained in tilting and shaking table tests. However, this method cannot evaluate the critical height and the failure zone of the ground obtained in the tests accurately. A modified pseudo-static limit equilibrium method is proposed in this study, which incorporates the tensile force at the crack plane of the ground appropriately. This modified method can give a reasonable evaluation of the critical height and the failure zone in the tilting test if the suitable strength ratio of the tensile to the compressive strength of the ground is incorporated. The method can also explain the shaking table test results provided that the amplification of ground acceleration is properly taken into account. The modified method is applied to evaluate the dynamic active earth pressure of the cement treated ground, in which the importance of incorporating the effect of the failure pattern is also emphasized.

\section{ACKNOWLEDGEMENTS}

The authors gratefully acknowledge Mr. Abe, H., Mr. Maruyama, K. and Mr. Akimoto, H. for conducting the model tests. The authors also acknowledge the Ministry of Land, Infrastructure and Transport, for financial support.

\section{NOTATION}

$A c c(z)$ : maximum ground response acceleration distribution with depth

$a_{\mathrm{w}}$ : binder factor ( = ratio of dry weight of cement to that of clay)

$B$ : horizontal distance of tensile crack from front face of ground

$B_{\mathrm{c}}$ : horizontal distance of tensile crack from front face of ground at critical height

$B_{\mathrm{c}} / H_{\mathrm{c}}$ : normalized horizontal distance of tensile crack from front face of the ground (extent of failure zone) at critical height

$D_{\text {c }}$ : horizontal distance of shear failure at ground surface at critical height

$\left(D_{\mathrm{c}} / H_{\mathrm{c}}\right)^{\mathrm{M}-\mathrm{o}}$ : normalized horizontal distance of shear failure at ground surface at critical height based on the conventional pseudo-static limit equilibrium method

$G$ : centrifugal acceleration

$G_{\mathrm{f}}$ : centrifugal acceleration at ground failure in tilting test

$H$ : height of ground

$H_{\mathrm{c}}$ : critical height of ground

$k_{\mathrm{h}}$ : horizontal seismic coefficient

$\left(k_{\mathrm{h}}\right)_{\mathrm{ave}}$ : average horizontal seismic coefficient within trapezoid soil block

$k_{\mathrm{h}}(z)$ : horizontal seismic coefficient distribution with depth

$P$ : resultant dynamic earth pressure

$P_{\mathrm{a}}$ : resultant dynamic active earth pressure

$S: \quad$ settlement of model ground in tilting test

$\alpha$ : ratio of tensile strength to unconfined compressive strength

$\beta$ : mobilization degree of $q_{\mathrm{u}}$ on shear plane

$\theta$ : inclination angle of model ground in tilting test $\gamma H_{\mathrm{c}} / q_{\mathrm{u}}: \quad$ normalized critical height

$\left(\gamma H_{\mathrm{c}} / q_{\mathrm{u}}\right)^{\mathrm{M}-\mathrm{O}}$ : normalized critical height based on the conventional pseudo-static limit equilibrium method

$\left(\gamma H_{\mathrm{c}} / q_{\mathrm{u}}\right)^{*}: \quad$ normalized critical height based on the conventional pseudo-static limit equilibrium method with neglecting effect of negative earth pressure $p_{\mathrm{a}}^{-}$

$\zeta$ : inclination angle of shear failure plane

$\zeta_{\mathrm{a}}:$ inclination angle of shear failure plane at active condition

\section{REFERENCES}

1) Dass, R. N., Yen, S.-C., Das, B. M., Puri, V. K. and Wright, M. A. (1994): Tensile stress-strain characteristics of lightly cemented sand, Geotech. Testing J., 17 (3), 305-314.

2) Horiuchi, S., Taketsuka, M., Odawara, T. and Kawasaki, H. (1992): Flyash slurry island: I. Theoretical and experimental investigations, J. of Materials in Civil Engrg., ASCE, 4 (2), 117-133.

3) Japanese Geotechnical Society (1990): JSF T 821-1990, Practice for Making and Curing Noncompacted Stabilized Soil Specimens.

4) Japanese Soil Mechanics Society (1994): Introduction to model tests for geotechnical engineering, 165 (in Japanese).

5) Kawasaki, H., Horiuchi, S., Akatsuka, M. and Sano, S. (1992): Flyash slurry island: II. Construction in Hakucho Ohashi project, J. of Materials in Civil Engrg., ASCE, 4 (2), 134-152.

6) Kitazume, M. (1998): Centrifuge model tests on failure of cement stabilized fly ash ground, Soils and Foundations, 38 (3), 143-152.

7) Kitazume, M. and Miyajima, S. (1996): Development of PHRI Mark II Geotechnical Centrifuge, Technical Note of the Port and Harbour Research Institute, (817), 4-33.

8) Kitazume, M. and Sato, T. (2002): Development of pneumatic flow mixing method and its application to Central Japan International Airport construction, Proc. of the 4th International Conference on Ground Improvement Techniques, Kuala Lumpur, 1-14.

9) Kitazume, M., Yoshino, N., Shinsha, H., Horii, R. and Fujio, Y. (2000): Field test on pneumatic flow mixing method for sea reclamation, Coastal Geotech. Engrg. in Practice (eds. by Nakase, A. and Tsuchida, T.), 647-652.

10) Kokusho, T., Kuno, G., Iwasa, M. and Yoshio, H. (2002): Basic experimental studies on mechanical properties of back-filled flowable fill under seismic loading effect, J. of Japan Soci. of Civil Engineers, (701) III-58, 219-229 (in Japanese).

11) Mikasa, M., Takada, N. and Yamada, K. (1969): Centrifugal model test of a rockfill dam, Proc. of the 7th Int. Conf. SMFE, Mexico, 2, 325-333.

12) Mononobe, N. and Matsuo, H. (1929): On determination of earth pressure during earthquake, Proc. of the World Engrg. Congress, Tokyo, 9, 177-185.

13) Okabe, S. (1924): General theory on earth pressure and seismic stability of retaining wall, J. of Japan Soci. of Civil Engineers, 10 (6), 1277-1323.

14) Steedman, R. S. (1991): Centrifuge modeling for dynamic geotechnical studies, Proc. of the 2 nd Int. Conf. Recent Advances in Geotech. Earthquake Engrg. and Soil Dynamics, St. Louis, 3, 2401-2417.

15) Steedman, R. S. and Zeng, X. (1990): The influence of phase on the calculation of pseudo-static earth pressure on a retaining wall, Géotechnique, 40 (1), 103-112.

16) Tatsuoka, F. and Kobayashi, A. (1983): Triaxial strength characteristics of cement-treated soft clay, Proc. of 8th European Conf. on SMFE, 1, 421-426.

17) Tatsuoka, F., Koseki, J., Tateyama, M., Munaf, Y. and Horii, N. (1998): Seismic stability against high seismic loads of geosyntheticreinforced soil retaining structures, Proc. of the 6th Int. Conf. on Geosynthetics, Atlanta, 103-142.

18) Terashi, M., Tanaka, H and Okumura, T. (1979): Engineering properties of lime-treated marine soils and D. M. M. Method, Proc. of the 6th Asian Regional Conf. on SMFE, 1, 191-194.

19) Tsuchida, T., Takeuchi, D., Okumura, T. and Kishida, T. (1996): Development of light-weight fill from dredgings, Proc. of 2 nd Int. 
Congress on Environmental Geotechnics, 415-420.

20) Whiteman, R. V. (1998): Experiment with earthquake ground motion simulation, Centrifuges in Soil Mechanics (eds. by Craig, W. H. et al.), 203-216.
21) Zeng, X. (1998): Seismic response of gravity quay walls. I: centrifuge modeling, J. of Geotech. and Geoenvironmental Engrg., 406-417. 